\title{
Infectious Diseases and the Development of Health Systems in Thailand
}

\author{
Visanu Thamlikitkul ${ }^{1}$, Viroj Tangcharoensathien ${ }^{2}$, \\ and Natth Bhamarapravati ${ }^{3}$ \\ ${ }^{1}$ Siriraj Hostpital, Mahidol University, Bangkok, Thailand \\ ${ }^{2}$ Ministry of Public Health, Nonthaburi, Thailand \\ ${ }^{3}$ Mahidol University Salaya, Nakhonpathom, Thailand
}

\section{HISTORY AND CURRENT STATUS OF INFECTIOUS DISEASES IN THAILAND}

Infectious diseases have been a major public health problem in Thailand for the past several centuries. Most infectious diseases in earlier days were food and water-borne diseases, vector-borne diseases, and infectious diseases related to poor sanitation (Wright and Breakspears, 1903; Beek, 2001). Some infectious diseases have now been eradicated, for example smallpox. The last case of smallpox in Thailand was documented in 1962. Some diseases have been brought under control by vaccines, such as diphtheria, pertussis, tetanus, poliomyelitis, and measles. However many infectious diseases continue to be public health problems such as acute respiratory tract infections, acute diarrhea, tuberculosis, dengue hemorrhagic fever, malaria, endemic infectious diseases such as melioidosis, and parasitic infestation e.g., opisthorchiasis. Like other countries, Thailand is faced with emerging infectious diseases, especially HIV/AIDS, and re-emerging diseases such as leptospirosis. Several emerging infectious diseases originating in neighboring countries such as severe acute respiratory syndrome (SARS), avian flu, and Nipah virus infections are also a threat to Thai people. Moreover, infectious diseases due to drug resistant microorganisms e.g., drug resistant Streptococcus pneumoniae, methicillin-resistant Staphylococcus aureus, and multi-drug resistant gramnegative bacilli have also been increasing.

There are 47 infectious diseases documented in the current Thai Communicable Diseases Act. These include cholera, plaque, smallpox, yellow fever, meningococcal infections, diphtheria, pertussis, tetanus, poliomyelitis, measles, rubella, mumps, chicken pox, influenza, encephalitis, dengue fever, rabies, hepatitis, hemorrhagic conjunctivitis, food poisoning, dysentery, amoebiasis, typhoid fever, paratyphoid fever, typhus fever due to Rickettsia prowazekii, scrub typhus, murine typhus, tuberculosis, leprosy, 
malaria, anthrax, trichinosis, yaws, leptospirosis, syphilis, gonorrhea, non-specific urethritis, chancroid, granuloma inguinalae, lymphogranuloma venereum, relapsing fever, acute diarrhea, chronic tropical ulcer, filariasis, HIV/AIDS, acute flaccid paralysis and SARS. Five diseases are classified as dangerous diseases, namely cholera, plaque, smallpox, yellow fever, and SARS. Any cases of the following diseases must be reported to the local health authority: cholera, plaque, smallpox, yellow fever, diphtheria, tetanus neonatorum, poliomyelitis, encephalitis, rabies, typhus fever due to Rickettsia prowazekii, anthrax, trichinosis, meningococcal infections, yaws, acute flaccid paralysis, and SARS.

According to the official documents of the Ministry of Public Health (MoPH) on the Burden of Disease and Injuries in Thailand in 1999, infectious diseases comprised $21 \%$ of the total of 9.6 million Disability Adjusted Life Years (2 million DALYs) (MoPH, Thailand, 2002; MoPH, Thailand, 2003a). HIV/AIDS accounted for a majority of the infectious disease burden, with 1.3 million DALYs, or $72 \%$ of the total infectious disease burden. The other major infectious diseases that contributed to the DALYs in Thailand were acute respiratory tract infections in children, and tuberculosis. Although HIV/AIDS has been the major infectious disease problem in Thailand over the past decade, it will be addressed elsewhere. This chapter will focus primarily on epidemiology and the current status of infectious diseases other than HIV/AIDS in Thailand over the past several decades, during which time a disease surveillance system has been well established. Some major infectious diseases under surveillance will be described. Morbidity and mortality data for most of the infectious diseases described in this chapter come from the annual epidemiological surveillance report prepared by the Bureau of Epidemiology, Department of Disease Control, MoPH from 1977 to 2002. It should be mentioned that the morbidity and mortality data collected by the MoPH is likely to be an under-estimate, and this data should therefore be considered as a minimum estimate of what is probably the actual reality.

\section{Acute Gastroenteritis}

Acute gastroenteritis includes acute diarrhea, food poisoning, dysentery and severe diarrhea. Cholera was the major leading cause of morbidity and mortality in Thailand in the 1900s. An epidemic of cholera in 1890 resulted in moving the Thai capital from Uthong to Krungsri Ayudaya. The morbidity rate of acute gastroenteritis per 100,000 population has been increasing, from 264 in 1977 to 1800 in 1991, to 2000 in 2002 as shown in Figure 1. However the case fatality rate has been decreasing, from $0.5 \%$ in $1977-1978$ to $0.1 \%$ or less since 1982. The decrease in the case fatality rate was primarily due to improvements in sanitation and personal hygiene, and oral rehydration therapy.

Acute gastroenteritis is still a common cause of morbidity and mortality in children under age five. The common micro-organisms causing acute gastroenteritis documented by stool or rectal swab cultures in 1998 and in 1999 collected from 23 hospitals located in all regions of Thailand revealed that $18 \%-$ $38 \%$ were Salmonella (more than $90 \%$ were non-typhoidal Salmonella), 21\%-36\% were Vibrio parahemolyticus, $8-12 \%$ were Escherichia coli, 9\%-22\% were Shigella (most of them were Shigella sonnei and Shigella flexneri), 2\%-5\% were Aeromonas 2\%-3\% were Plesiomonas and 3\%-5\% were Vibrio cholerae (Ministry of Public Health (MoPH), Thailand, 1998; MoPH, Thailand, multiple years). There were nine major outbreaks of cholera during 1900 to 1980 , which infected more than 80,000 patients and caused more than 30,000 deaths. The case fatality rate decreased from $72 \%$ in 1918 to $3 \%$ in 1980 . The first six major outbreaks were caused by the Vibrio cholerae serogroup $\mathrm{O} 1$ biotype classical whereas the Vibrio cholerae serogroup O1 biotype El-Tor serotype Ogawa and Inaba was the cause of the cholera since 1963. El Tor cholera usually causes less severe diarrhea 


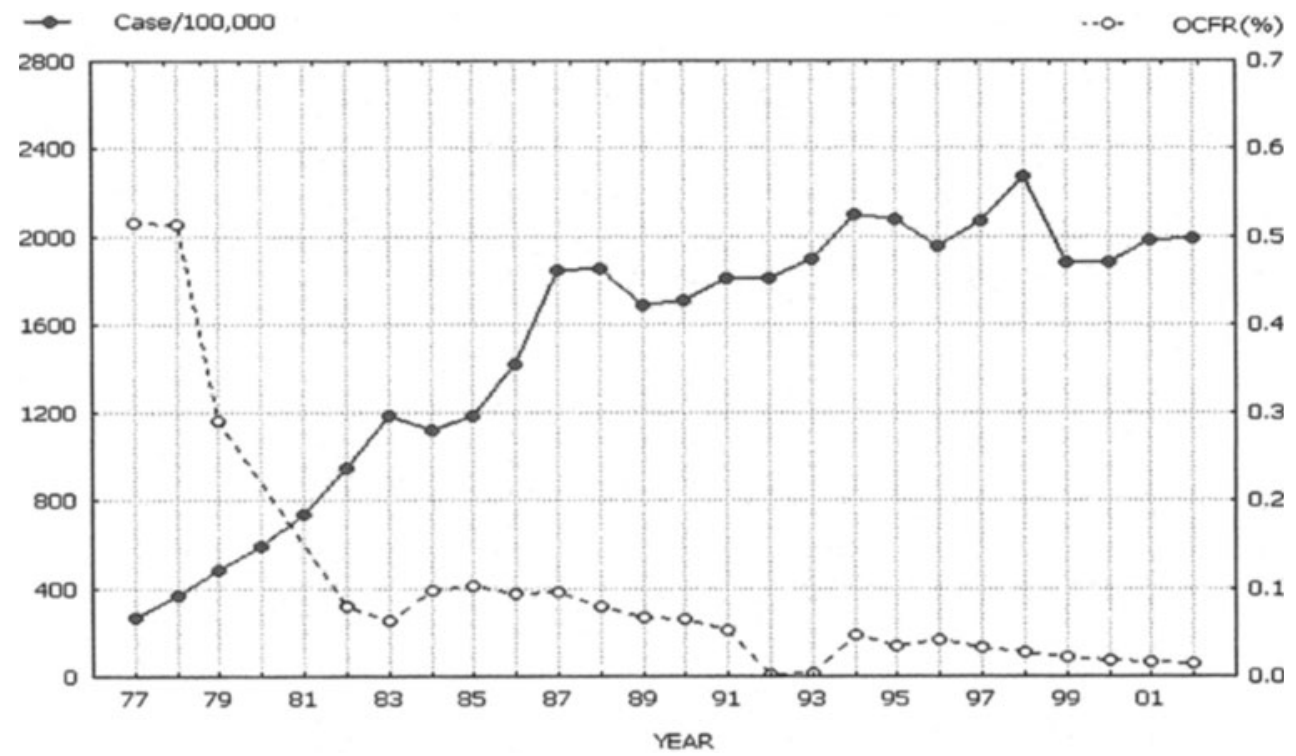

FIGURE 1. Morbidity and case fatality rate (CFR) for acute gastroenteritis (Ministry of Public Health, Thailand, 1997-2002)

with a much lower case fatality rate than classical cholera. Vibrio cholerae serotype Ogawa was a predominant serotype during 19931994 epidemic, whereas serotype Inaba has been the most common serotype ever since.

The cholera epidemics during 1992 and 1994 were caused by Vibrio cholerae non-O1 (O139) and since that time this strain of Vibrio cholerae has been found only rarely. Diarrheagenic E.coli strains isolated from patients with acute diarrhea in 1998 were enteropathogenic E.coli (86\%), enteroaggregative E.coli (11\%), enterotoxigenic E.coli (2\%) and enteroinvasive E.coli (1\%). Less than $50 \%$ of Shigella isolated from stools was sensitive to ampicillin, tetracycline and cotrimoxazole whereas $40 \%$ to $75 \%$ of nontyphoidal Salmonella was sensitive to ampicillin and co-trimoxazole. Nearly all strains of non-typhoidal Salmonella and Shigella were sensitive to fluoroquinolones and third generation cephalosporins (MoPH, Thailand, 1998; $\mathrm{MoPH}$, Thailand, 1999; Isenbarger et al., 2002). Susceptibility of Aeromonas to ampicillin, co-trimoxazole and norfloxacin were $10 \%, 70 \%$, and $85 \%$ respectively. The Vibrio cholerae serotype Ogawa was susceptible to tetracycline and co-trimoxazole prior to 1996. Since 1996, more than 70\% of Vibrio cholerae serotype Ogawa have been resistant to cotrimoxazole. Resistance to tetracycline was up to $50 \%$ in 2000 and then declined to $10 \%$ in 2002. Most strains of the Vibrio cholerae serotype Inaba were still sensitive to tetracycline and co-trimoxazole. Vibrio cholerae O139 was usually resistant to co-trimoxazole but still sensitive to tetracycline. Almost all strains of Vibrio cholerae were sensitive to fluoroquinolones. Antibiotic susceptibility profiles of Vibrio cholerae, non-typhoidal Salmonella Shigella Aeromonas against ampicillin, tetracycline and co-trimoxazole may vary according to geographical areas and species of the organism. Vibrio parahemolyticus is almost always sensitive to tetracycline, co-trimoxazole, and fluoroquinolones.

Studies of acute gastroenteritis in children have elucidated many trends and characteristics of the disease. Campylobacter jejuni was isolated in $27 \%$ of children presenting with dysentery at Children's Hospital in Bangkok during 1998-2000. Campylobacter 


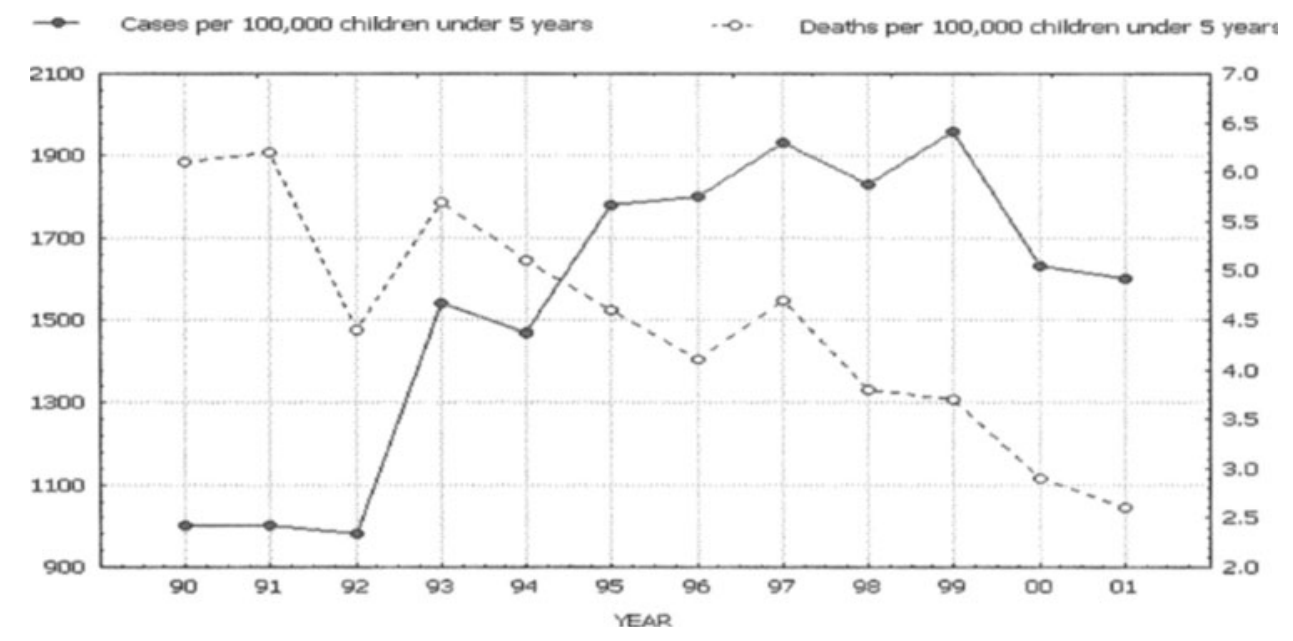

FIGURE 2. Morbidity and mortality rate for acute respiratory tract infections in children under 5 years (Ministry of Public Health, Thailand, 1997-2002)

jejuni was also a causative agent in a small outbreak of acute diarrhea in US troops deployed to Thailand in 1994 and it was the most common pathogen of acute dysentery in children (Bodhidatta et al., 2002; Murphy et al., 1996). Most of the Campylobacter isolates were resistant to ciprofloxacin but some were resistant to macrolides. Rotavirus accounted for $6 \%-7 \%$ of acute diarrhea in children attended Children's Hospital in Bangkok in 2000 \& 2001, and it was the third most common cause next to Aeromonas (13\%) and Salmonella (10.5\%) (Children's Hospital, 2000 and 2001). Rotavirus was found in $27 \%$ to $34 \%$ of cases of acute diarrhea in young children and G1 was the most prevalent serotype followed by G2, G4 and G3, respectively (Maneekarn and Ushijima, 2000). Toxins produced by S.aureus, E.coli, Bacillus cereus, Clostridium perfringens in addition to enteric bacteria, cause food poisoning.

\section{Acute Respiratory Tract Infections (ARI) in Children under Age Five}

Acute respiratory infections are the most common illnesses in childhood, comprising approximately $50 \%$ of all illnesses in children under age five and $30 \%$ in children ages five through twelve. The incidence of pneumonia in children under age five was $1 \%-1.9 \%$ during 1990 and 2001 as shown in Figure 2. The death rate per 100,000 children under age five due to pneumonia during the same period decreased from six deaths in 1990 to 2.6 deaths in 2001 as shown in Figure 2. This data indicated that the morbidity of pneumonia in children under age five has not changed while mortality has decreased. The causative agents of ARI in Thai children are bacteria and viruses (MoPH, Thailand, 1981; Sunakorn $e t$ al., 1990; Suwanjutha et al., 1990; Suwanjutha et al., 2002; Siritantikorn et al., 2002; Vathanophas et al., 1990). Otitis media and sinusitis are caused by Streptococcus pneumoniae and Haemophilus influenzae, whereas Streptococcus pyogenes is found in patients with pharyngitis and tonsillitis. Pneumonia and empyema may be caused by Staphylococcus aureus, Streptococcus pneumoniae, and Haemophilus influenzae. Nasopharyngeal swabs obtained from children under age five with upper respiratory infections (URI) and pneumonia during 1993 and 1994 revealed that S. pneumoniae was recovered in $37 \%$ of URI patients and $31 \%$ of pneumonia patients, and $H$. influenzae was recovered in $40 \%$ of URI patients and $37 \%$ of pneumonia 
patients (Bamrungtrakul et al., 1994). Thirtyseven percent of $S$. pneumoniae isolates were resistant to penicillin ( $\mathrm{MIC} \geq 0.1 \mu \mathrm{g} / \mathrm{ml}$ ) and $26 \%$ to co-trimoxazole. Twenty-one percent of $H$. influenzae isolates were resistant to ampicillin and $24 \%$ to co-trimoxazole. Most penicillin resistant $S$. pneumoniae belonged to the Spanish pandemic clone $23 \mathrm{~F}$ and Spanish-French international clone 9V (Dejsirilert et al., 1999). The prevalence of penicillin resistant $S$. pneumoniae in Thailand has been increasing to $56 \%$ in 1997 and $61 \%$ in 2000. The overuse of antibiotics is a major contributing factor to this high prevalence of antibiotic resistant $S$. pneumoniae. Between $30 \%$ and $60 \%$ of children with upper respiratory infections that were usually caused by viruses have been treated with antibiotics. Chlamydia trachomatis is also a causative agent of lower respiratory infections in children (MoPH, Thailand, 1998). The common cold, bronchitis, bronchiolitis and pneumonia are caused by viruses, especially the respiratory syncytial virus (RSV), influenza, parainfluenza, and adenovirus (MoPH, Thailand, 1981; Sunakorn et al., 1990; Suwanjutha et al., 1990; Suwanjutha et al., 2002; Siritantikorn et al., 2002; Vathanophas et al., 1990).

\section{Tuberculosis (TB)}

Prevention and control of tuberculosis in Thailand was officially endorsed by Prince Mahidol in 1920. Tuberculosis was the second most common cause of death in Thais after malaria at the end of the World War II. The anti-TB society and hospitals for TB were established later. TB centers were founded in various parts of the country. The three national surveys of tuberculosis done in 1962, 1977, and 1991 revealed that the morbidity rate diagnosed by chest $\mathrm{x}$-ray was $2.1 \%, 1.4 \%$, and $1.01 \%$, and the infectious case rate was $0.5 \%$, $0.31 \%$, and $0.24 \%$ respectively (Sriyabhaya et al., 1993). The infection rate of children 0 14 years of age was found to be $15.2 \%$ in 1977 ; $8.9 \%$ in 1983; and $5.18 \%$ in 1987 , making the annual risk of infection $4.9 \%, 2.3 \%$, and $2.0 \%$ respectively (Sriyabhaya et al., 1993). These observations showed a significant reduction in the TB burden in Thailand. However the annual morbidity rate of tuberculosis since 1992 has increased from 20,000 cases (35 per 100,000 population) to more than 30,000 cases (50 per 100,000 population) in 1999 and thereafter, as shown in Figure 3. Based on prevalence and incidence rates, it is estimated that 80,000 to 100,000 people are infected with tuberculosis every year.

The primary reasons for this reemergence of tuberculosis in Thailand are HIV infections, and the influx of migrants and illegal workers from neighboring countries. A strong association between HIV infection and a rapid increase in TB cases has been observed (Siriarayapon et al., 2002). The TB registry data from a hospital in northern Thailand showed that the annual number of TB cases nearly doubled between 1990 and 1994 and the prevalence of HIV-seropositive TB patients rose from $1.5 \%$ of all TB patients in 1990 to $45.5 \%$ in 1994 (Yanai et al., 1996). The prevalence of HIV infections in new cases of TB at the Chest Hospital in central Thailand was 22\% during 1995 and 1996 (Punnotok et al., 2000). The clinical manifestations of TB in HIV infected patients on initial presentation included a low-grade fever, cough, weight loss, lymphadenopathy with pancytopenia, and lung infiltrates (Putong et al., 2002). The prevalence of primary drug resistance to TB during 1996 and 1998 at a hospital in northern Thailand was $13.2 \%$ to isoniazid, $10.8 \%$ to rifampicin, $15.6 \%$ to streptomycin, $5.8 \%$ to ethambutol; and multidrug resistance (MDR), i.e., resistance to at least both isoniazid and rifampicin, was observed in $6.3 \%$ of cases (Yoshiyama et al., 2001). HIV infection was found to be a risk factor for infection with resistant $M$. $t u$ berculosis (Yoshiyama et al., 2001). A study conducted in 1995-1996 demonstrated that HIV-positive patients with first-episode TB were more likely to have resistant Mycobacterium tuberculosis strains when compared to TB patients without HIV infection (Punnotok 


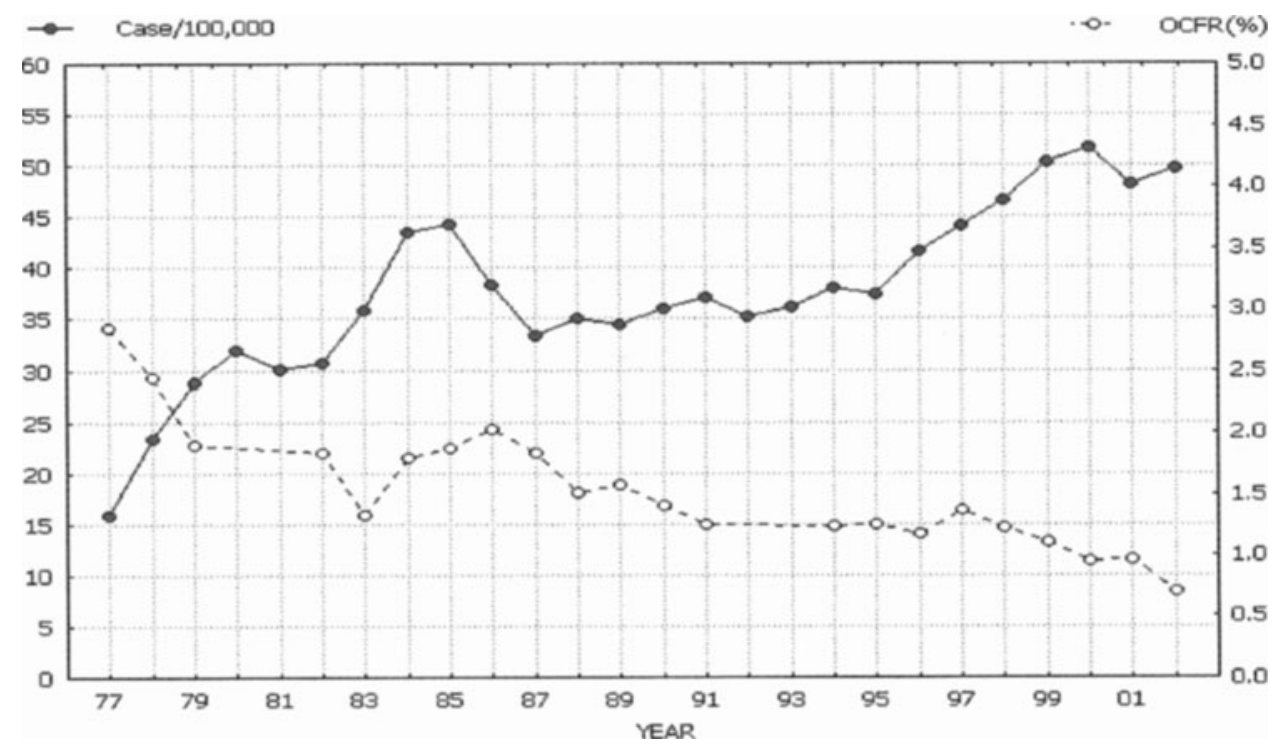

FIGURE 3. Morbidity and case fatality rate (CFR) for tuberculosis (Ministry of Public Health, Thailand, 1997-2002)

et al., 2000). The prevalence of drug resistance in patients with HIV infection as compared to patients without HIV infection was $10.9 \%$ vs $3.5 \%$ for isoniazid, $9.4 \%$ vs $2.9 \%$ for rifampicin, and $5.2 \%$ vs $0.4 \%$ for at least isoniazid and rifampicin (multidrugresistant TB). A study on drug resistant $M$. tuberculosis in a university hospital in northeastern Thailand between 1995 and 2000 revealed the prevalence of $8.2 \%$ resistance to rifampicin, $4.2 \%$ to isoniazid, $4.3 \%$ to ethambutol, $3.7 \%$ to streptomycin, $3 \%$ to kanamycin, $2.3 \%$ to ofloxacin, and $2.4 \%$ to at least isonazid and rifampicin (Reechaipichitkul, 2002). The factors associated with drug resistant tuberculosis were HIV infection and having a history of prior treatment. A high prevalence of MDR TB, 19.5\%, was reported in 154 consecutive tuberculosis prisoners in central Thailand in 2000 (Pleumpanupat et al., 2003).

Treatment of drug resistant TB in HIV infected patients was costly and the outcome was unsatisfactory (Yanai et al., 1996; Putong et al., 2002; Reechaipichitkul, 2002; Kamolratanakul et al., 2002). Although TB chemoprophylaxis had been found to be beneficial in
HIV infected patients with a previous exposure to $M$. tuberculosis, this preventive measure has a limited use in Thailand due to a low predictive value in detecting $M$. tuberculosis infection in HIV-infected persons by tuberculin skin test and a high prevalence of primary drug resistance (Yanai et al., 1997). Tuberculosis is not only a threat to patients with HIV infection but also to the general public who come in contact with the patients, especially health care workers (Yanai et al., 2003).

\section{Rabies}

The first report of a victim of human rabies in Thailand was a Thai princess who was bitten by a rabid dog in 1912. She did not receive any post-exposure treatment since rabies vaccine and rabies anti-serum were not available in Thailand at that time. She developed rabies and died three months after being bitten by the dog. Her death resulted in the establishment of the Queen Sauvabha Memorial Institute. Since that time, a diagnostic laboratory for rabies and rabies vaccine 


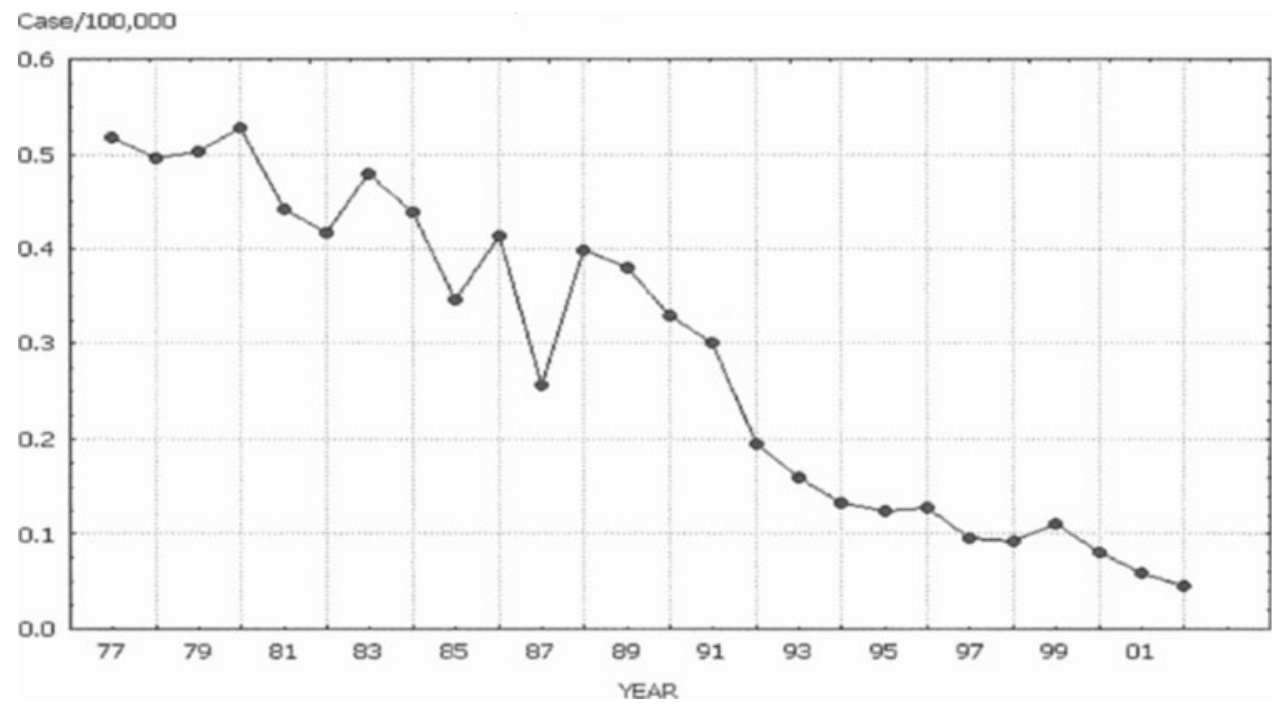

FIGURE 4. Morbidity rate for rabies (Ministry of Public Health, Thailand, 1997-2002)

production has been established in this institute. Since 1967, there have been 250 to 300 cases of human rabies per year, a rate of $0.6-0.7$ per 100,000 population $(\mathrm{MoPH}$, multiple years). During 1977 to 1991, approximately 200 cases of human rabies per year, a rate of 0.5 per 100,000 population, were identified. Since 1992 the number of human rabies has been decreasing, from 113 cases $(0.2$ per 100,000 population) in 1992 to 28 cases $(0.05$ per 100,000 population) in 2002 as shown in Figure 4.

Rabies in humans is more common in males than females and is more common in children aged 10 years old and under. Human rabies has been reported in all regions of Thailand, year round, with a slight increase from November to March. The continuous decrease in human rabies cases is primarily due to post-exposure treatment with vaccination and immuno-prophylaxis. Rabies post-exposure vaccinations were given to 35,$000 ; 70,000$; 130,$000 ; 160,000 ; 200,000$ and more than 300,000 dog bite patients in 1967, 1981, 1993, 1994, 1999 and 2001, respectively (Panichabhongse, 2001). This observation implies that the number of dog bite victims has been increasing and rabid dogs are still prevalent.
Rabies vaccinations have been given to dogs since 1956. The rate of rabies in dogs has decreased yearly since 1993, from 52 per 100,000 dog population in 1993 to 21 in 1999 (Panichabhongse, 2001).

Submission of 4000 dog brains for rabies virus detection revealed a positive rate of $33 \%$ in 1997; the rate has decreased to $29 \%$ in 2001 (Kingnate et al., 1997). Dogs are the main reservoir species for rabies and are responsible for $96 \%$ of human deaths. Cats are responsible for $3 \%-4 \%$ of human deaths and other animals and wildlife for $1 \%$. Dogs without an owner were 2.2 times more likely to have rabies than dogs with an owner.

\section{Acute Pyrexia of Unknown Origin (PUO)}

Fifty to eighty thousand cases of patients with acute pyrexia of unknown origin were reported during 1977 and 1979 (MoPH, multiple years). The number increased from 100,000 to 200,000 cases between 1980 and 1984 , and to over 200,000 cases per year since 1985. The annual rate has been about 400 per 1000,000 population since 1984 , as shown in Figure 5. However, the case fatality rate was less than $0.1 \%$, as also shown in Figure 5. 


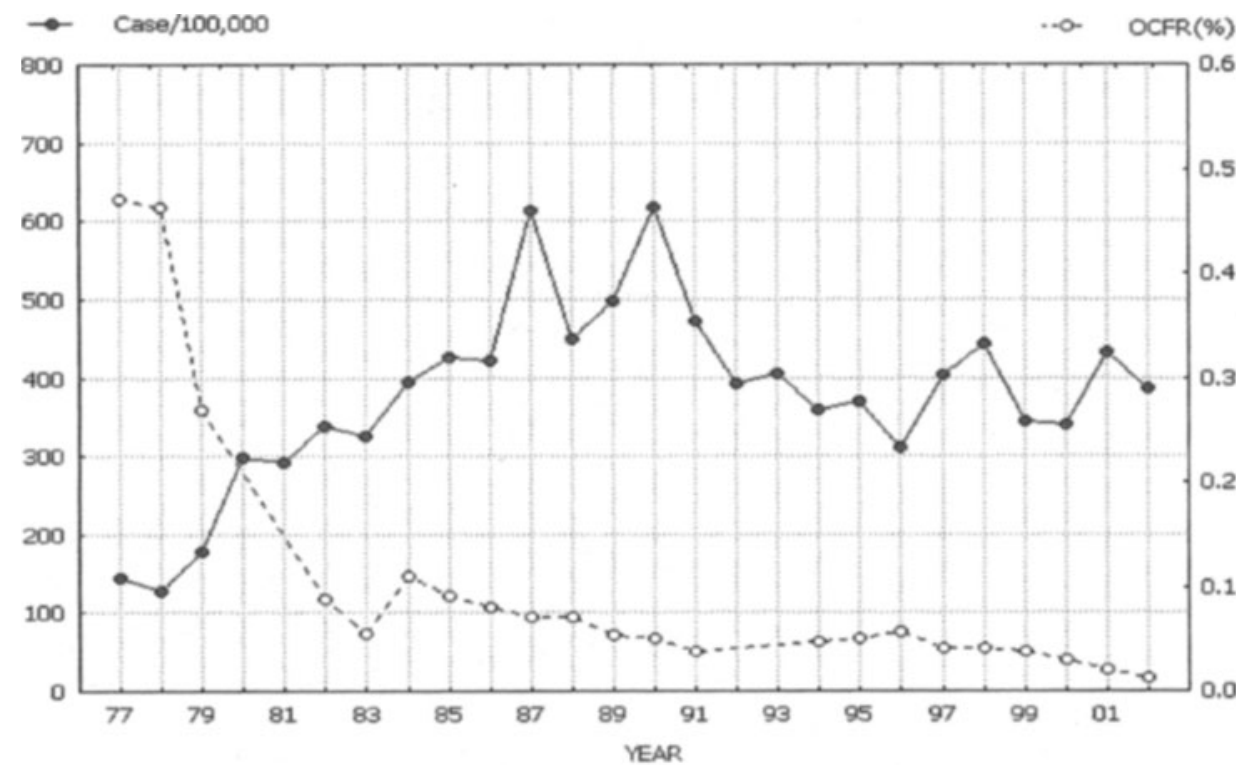

FIGURE 5. Morbidity and case fatality rate (CFR) for acute pyrexia of unknown origin (Ministry of Public Health, Thailand, 1997-2002)

Several attempts have been made to determine the cause of fever in these patients. A study of 294 acute PUO cases during 19661968 revealed arbovirus infections in $16.3 \%-$ $18.7 \%$, scrub typhus in $9.7 \%-14.2 \%$, leptospirosis in $2.2 \%-5.8 \%$, murine typhus in $0.7 \%-1.2 \%$, and brucellosis in $0.6 \%$. A study of 1218 patients with acute PUO during 19911992 revealed that the cause was known in $38.7 \%$ of cases. The causes of acute PUO were scrub typhus $7.5 \%$, influenza $6 \%$, dengue $5.7 \%$, murine typhus $5.3 \%$, bacteremia $3 \%$, enteric fever $1.9 \%$, chikungunya $1.1 \%$, leptospirosis $1.1 \%$, melioidosis $0.9 \%$, Japanese Encephalitis virus infection $0.6 \%$, and unknown in $61.3 \%$ of cases (Leelarasamee, 2000).

A recent study during 2001-2002 revealed that $31.1 \%$ of PUO cases were associated with leptospirosis, $20.7 \%$ were associated with rickettsioses which included scrub typhus, murine typhus and the spotted fever group, $2.4 \%$ were bacterial infections, $3.9 \%$ were associated with miscellaneous causes, and $41.9 \%$ were unknown (Yupin Suputtamongkol, personal communication, June
2003). Several other studies have also shown that leptospirosis, rickettsioses including the spotted fever group and arbovirus infections were causes of acute PUO (Silpapojakul et al., 1993; Sirisanthana et al., 1994; Silpapojakul et al., 1991; Watt and Jongsakul, 2003; Endy et al., 2002). Q fever was recently found to be the cause of fever in nine patients with acute PUO (Suputtamongkol et al., 2003). Acute PUO continues to be a common public health problem and further research on its epidemiology and causes are still needed.

\section{Dengue Hemorrhagic Fever (DHF)}

The first case of DHF in Thailand was reported at Siriraj Hospital in 1951. There was an epidemic of DHF in Bangkok and Thonburi in 1958. This epidemic affected 2418 patients with 240 deaths. Since 1958, there have been epidemics of DHF every other year or every several years, and the number of cases have increased as more areas of the country experience epidemics. DHF has become an endemic disease in Thailand with periodic epidemic outbreaks. The endemic mode of DHF 


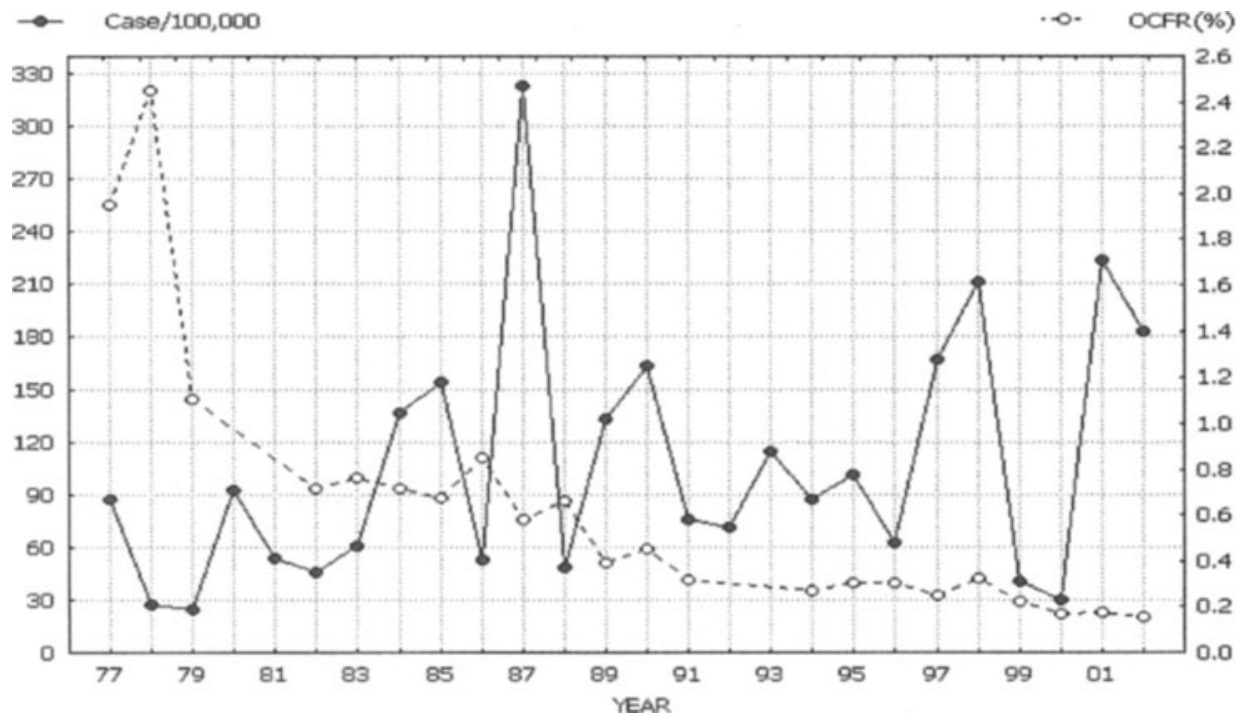

FIGURE 6. Morbidity and case fatality rate (CFR) for dengue hemorrhagic fever (Ministry of Public Health, Thailand, 1997-2002)

corresponds to the cyclic seasonal pattern, with incidence reaching its peak during the hot and rainy seasons (May-October). The epidemic mode is a non-cyclic pattern and corresponds to important non-seasonal rises in the incidence of DHF. Major epidemics over the past several decades occurred in 1977, 1980, 1984, 1985, 1987, 1989, 1990, 1993, $1995,1997,1998,2001$, and 2002, as shown in Figure 6. During 1958 and 1963, the number of cases per year was 1,000 to 4,000 . Since 1964 , the number of cases for each epidemic has been over 10,000 cases. The 1987 epidemic was the worst, with 152,840 cases and 785 deaths (Ungchusak and Kunasol, 1987).

A retrospective study of spatial and temporal variations of DHF incidence in Thailand during 1983 and 1995 revealed that $52.4 \%$ of DHF cases occurred during epidemic months (Barbazan et al., 2002). From 1983 to 1990, three major epidemics lasting 10-12 months occurred at 10- to 15-month intervals and affected almost the entire country simultaneously (50-70 provinces). From 1991 to 1995 , epidemics did not affect as many provinces simultaneously (less than 30), and were less differentiated than during the inter-epidemic periods. In many provinces a 2- to 4-month interruption was observed during the dry and cold seasons, the incidence decreasing to the "normal" level, followed by a short reemergence (lasting 2-3 months) of the epidemic pattern.

Most of the DHF cases have been in children under 15 years old. DHF is characterized by fever, bleeding diathesis with thrombocytopenia, and a tendency to develop hypovolemia due to vasculopathy. Primary dengue infection is usually less severe than a secondary infection. Preexistent dengue immunity is a risk factor for developing dengue hemorrhagic fever. The risk of developing dengue shock syndrome (DSS) is greatest following an anamnestic dengue infection, particularly if the most recent infection was with the dengue 2 virus. Only $1 \%$ to $3 \%$ of patients with dengue fever develop DSS. Most of the infected patients are mildly symptomatic and the early symptom complex of acute dengue virus infection is protean and difficult to distinguish from other causes of febrile childhood illnesses (Endy et al., 2002).

Unusual manifestations of DHF, especially cerebral and hepatic manifestations 
were not infrequently observed (Nimmannitya et al., 1987; Pancharoen and Thisyakorn, 2001). Classical HLA class I alleles were associated with the clinical outcome of exposure to dengue virus in previously exposed and immunologically primed individuals (Stephens et al., 2002). An increased dengue disease severity was correlated with a high viremia titer, secondary dengue virus infection, and DEN-2 virus type (Vaughn et al., 2000). DHF was caused by Dengue virus type $1,2,3,4$. DEN-3 was the most frequent serotype in primary dengue, $\mathrm{DEN}$ 2 in secondary and in dengue hemorrhagic fever (Nisalak et al., 2003). The predominant dengue serotype varied by year: DEN-1 from 1990-92, DEN-2 from 1973-86 and 198889; DEN-3 in 1987 and 1995-99; and DEN-4 from 1993-94. Only DEN-3 was associated with severe outbreak years. The case fatality rate of DHF has decreased from $10 \%$ to $3 \%$ during the 1960 s, to $2 \%$ in the 1970 s, to $0.7 \%$ in the $1980 \mathrm{~s}$, and to $0.3 \%$ or less since 1991 as shown in Figure 6.

Prevention and control of DHF depends on control of the female Ades mosquito vector and vaccine. Currently the only effective way to avoid dengue infection in areas where the disease is endemic or epidemic is to avoid being bitten by infected Ades egypti mosquitoes through the use of personal insect repellent and other insect barriers. There is no dengue vaccine currently available for widespread public health use. Thai researchers have developed a dengue tetravalent live-attenuated vaccine (Sabchareon et al., 2002). A study of the safety and immunogenicity of two doses of vaccine in flavivirus-seronegative Thai adults showed that the first dose was the more reactogenic and $58 \%$ of the recipients seroconverted against 3 or more serotypes; $35 \%$ seroconverted against all four. After the second dose, seroconversion was $76 \%$ and $71 \%$, respectively. All subjects seroconverted to serotype 3 after one dose. Serotype 4 elicited the lowest primary response but the highest increase in seroconversion after the second dose (Sabchareon et al., 2002).
Further research and development on a safe and efficacious dengue vaccine is urgently needed. DHF continues to be a heavy health burden in terms of high morbidity and huge socioeconomic impact (Kantachuvessiri, 2002). The goals of the Thai National Dengue Prevention and Control Plan (NDPCP) for DHF are to reduce the morbidity rate of dengue infection to 50 or less per 100,000 population, and the case fatality rate to $0.2 \%$ or less; and to reduce the mosquito breeding places measured by the Breteau index to below 50 and the container index to below 10 . Interventions aimed at achieving the aforementioned goals have been employed. In addition to DHF, a disease caused by the chikungunya virus, which has similar clinical manifestations and transmission, was observed to be prevalent in Thailand (Thaikruea et al., 1997).

\section{Malaria}

Malaria was first documented in Thailand in 1660 and it remains a significant infectious disease leading to morbidity and mortality in Thailand. In 1947, there were 52,000 deaths due to malaria, with a death rate of 297 per 100,000 population; the number of malaria cases was 3.8 million in 1949 (Bumrasnaradul, 1967). The morbidity rate was higher than 200 cases per 100,000 population during 1980 and 1990 and decreased to less than 100 since 2000 as shown in Figure 7. However, the morbidity rate in 1998 and 1999 increased to more than 100 per 100,000 population due to imported cases along the international borders and a reduction in vector control during the economic crisis in Thailand (Chareonviriyaphap et al., 2000; Wiwanitkit, 2002).

Malaria occurs more frequently in the summer and rainy seasons (March to September). Males are more affected, and the disease affects all age groups, though it is found more frequently in those aged 15 to 44 . All four human malaria parasites cause diseases in Thailand. Plasmodium falciparum and Plasmodium vivax account for more than $95 \%$ of 


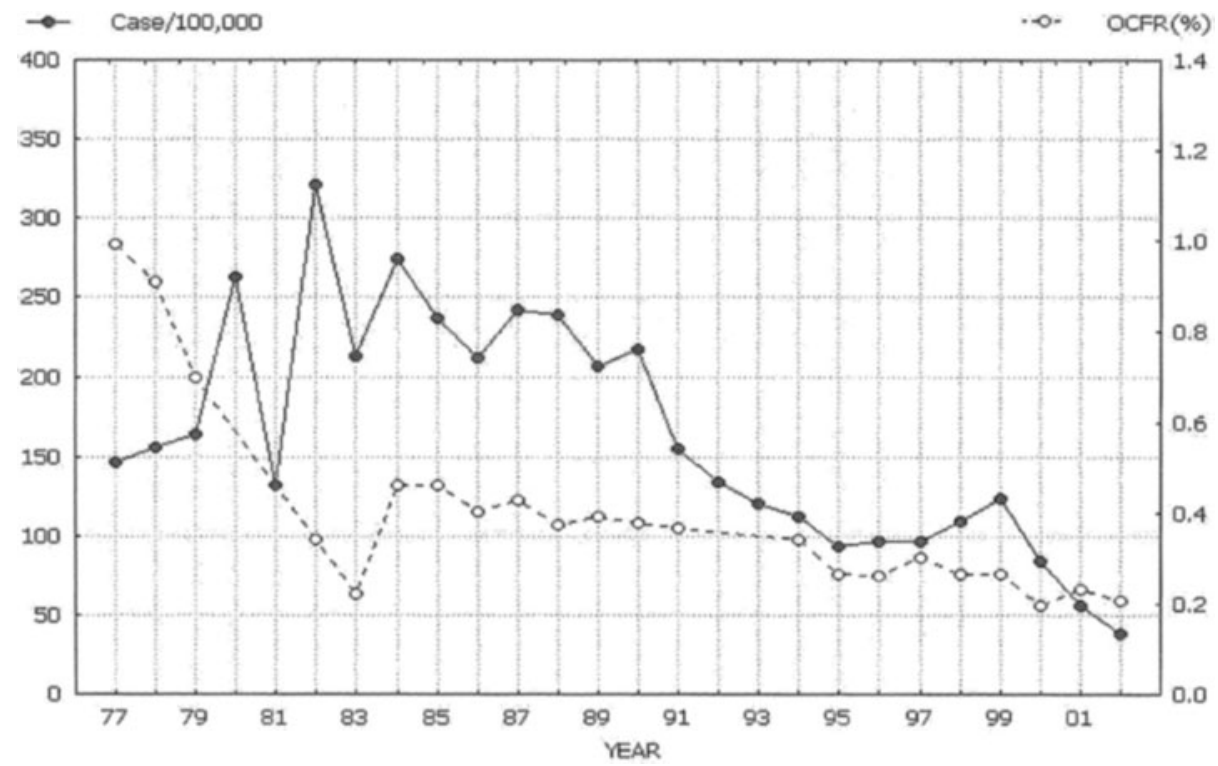

FIGURE 7. Morbidity and case fatality rate (CFR) for malaria (Ministry of Public Health, Thailand, 1997-2002)

the cases whereas Plasmodium malariae and Plasmodium ovale are very rare. During 1978 and 1985, $P$ falciparum accounted for $60 \%-$ $80 \%$ of cases, but after 1985 until $2002 P$ falciparum was responsible for $40 \%-60 \%$ of infections.

Drug resistant malaria has posed one of the most difficult problems in malaria control over the past decades (Wongsrichanalai et al., 2002). Chloroquine resistant Plasmodium falciparum was first reported in Thailand in 1961 and chloroquine is no longer effective for falciparum malaria. Resistance to sulfadoxine-pyrimethamine was first noted on the Thai-Cambodian border and more than $90 \%$ of $P$. falciparum were resistant after this drug replaced chloroquine for a decade (Wongsrichanalai et al., 2002). Mefloquine had been effective for therapy of falciparum malaria until the late 1980s when resistance was first observed near the ThaiCambodian border. Mefloquine alone is no longer effective on the Thai-Myanmar and Thai-Cambodian borders, although it is still moderately useful in some endemic areas in and around Thailand. The role of mefloquine nowadays is to be used in combination with artemisinin derivatives. Resistances to quinine and artemisinin derivatives are considered uncommon and both drugs are still very effective if they are used in combination with another anti-malarial. P. falciparum resistant to more than two operational antimalarial compounds of different chemical classes (multi-drug resistance) is common at the Thai-Myanmar and Thai-Cambodia borders.

The factors that have contributed to widespread drug resistance in Thailand include wide availability of drugs, poor compliance, inappropriate therapy and selftreatment. Multidrug-resistant $P$. falciparum is being controlled within the framework of a general malaria containment program i.e., rapid case detection and treatment, and vector control in areas where transmission occurs. The currently effective regimen for therapy of falciparum malaria in Thailand, especially in the area with multi-drug resistance, is artesunate plus mefloquine or quinine plus tetracycline for uncomplicated falciparum malaria and intravenous quinine 


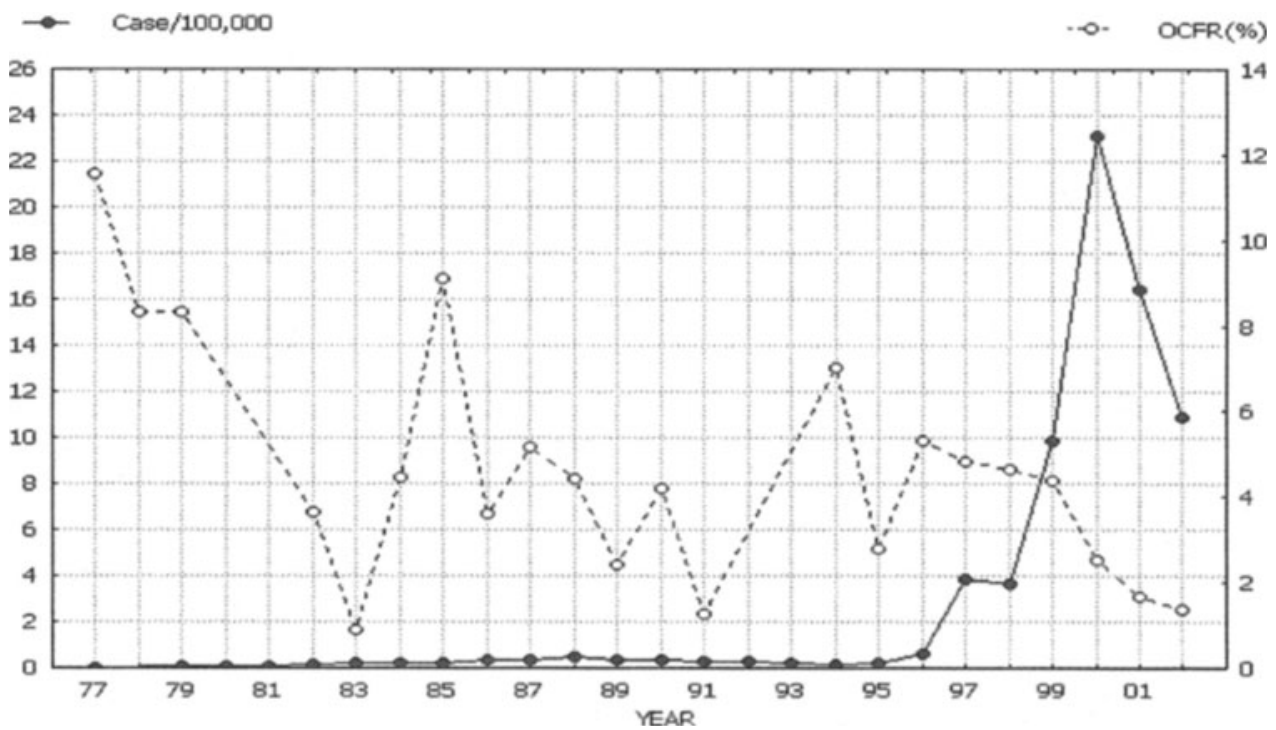

FIGURE 8. Morbidity and case fatality rate (CFR) for leptospirosis (Ministry of Public Health, Thailand, 19972002)

or artemisinin derivatives in cases of severe malaria. The cloroquine-primaquine regimen is still effective for therapy of vivax malaria (Congpuong et al., 2002).

The mortality rate of malaria in 1930 was greater than 400 cases per 100,000 population. The mortality rate per 100,000 population has been steadily decreasing to nearly 300 cases in 1947,14 in 1975,8 in 1980 , 2.3 in 1990 and 1.3 in 1997. The case fatality rate has been decreasing from $1 \%$ in 1977 to $0.2 \%$ in 2002 as shown in Figure 7 . Fatality is usually due to cerebral malaria and severe and complicated malaria. The reduction of morbidity and case fatality in malaria is partly due to programs using chemical insecticide to spray inside houses, promotion of bed-nets often impregnated with permethrin, establishment of a surveillance and control system through more than 500 malaria clinics and more than 15,000 malaria village volunteers, and the availability of more powerful antimalarials such as artemisinin derivatives. Biological control and environmental management to control malaria vectors have also been attempted. Vector control remains to be an important strategy in the fight against malaria in Thailand.

\section{Leptospirosis}

Leptospirosis was first reported in Thailand in four patients who developed the disease during the flood in Bangkok in 1942; two patients died (Yunibandu, 1943). Prior to 1996 , there were fewer than 200 cases of leptospirosis per year, and more cases were usually observed after flooding. The number of leptospirosis patients has increased to 14,285 ( 23 cases per 100,000 population) in 2000 , as shown in Figure 8 . This is clearly a reemerging disease. Geographic variability in the distribution of cases has been noted, i.e., more than $80 \%$ of cases were localized to the northeastern region. The demographic profiles of leptospirosis cases during epidemics remain unchanged. The disease is usually diagnosed during August to November. A highrisk group was found to be male farmers aged 15 to 45 years old. Risk factors for acquiring leptospirosis are walking through water, applying fertilizer in wet fields for more 


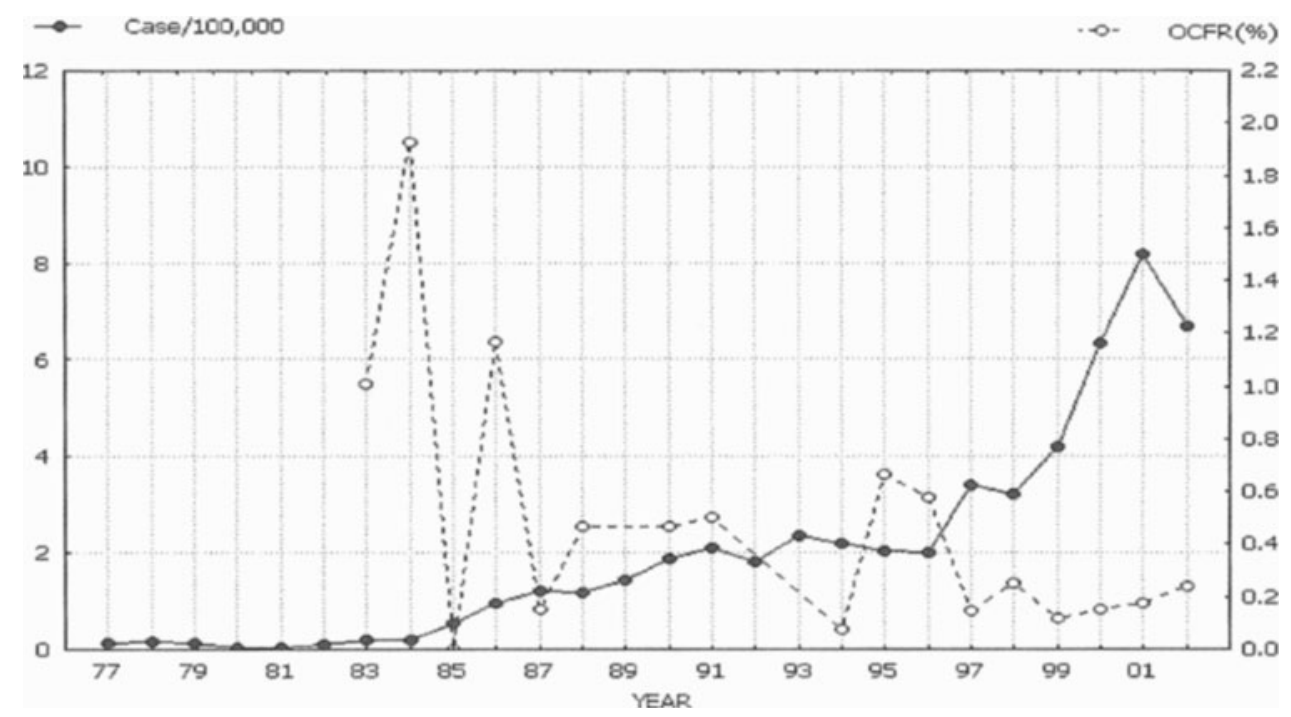

FIGURE 9. Morbidity and case fatality rate (CFR) for scrub typhus (Ministry of Public Health, Thailand, 19972002)

than 6 hours a day, plowing in wet fields for more than 6 hours a day, pulling out rice plant sprouts in wet fields for more than 6 hours a day, and traveling on potholed roads within 2 weeks (Tangkanakul et al., 2000; Tangkanakul et al., 2001).

Current clinical manifestations are not significantly different from cases recognized prior to 1996 . Yet, pulmonary complications seem to be more frequent and pulmonary hemorrhage is the leading cause of death. Microagglutination test of serum samples from patients revealed that the common serovars were bratislava, sejroe and pyrogenes which were different from icterohaemorrhagia and bataviae which were reported serovars in the past (Tangkanakul, 2002). However the most common serogroup of the leptospires isolated from patients' blood was autumnalis (Y. Suputtamongkol, personal communication, June 2003). The case fatality rate varied from $1 \%$ to $20 \%$. The case fatality rate during epidemics has been $1 \%$ to $10 \%$ as shown in Figure 8. Penicillin $\mathrm{G}$ and doxycycline are still the first line antibiotics used for therapy. Ceftriaxone has been demonstrated to be efficacious as well (Panaphut et al., 2003).
Marked differences in rodent population density and number of infected animals between epidemic and non-epidemic sub-districts have been found. Serological studies in rodents trapped in urban and rural areas in Thailand revealed that pyrogenes, sejroe and bataviae were predominant serovars (Wangroongsarb et al., 2002; Kositanont et al., 2003). The leptospires isolated from $14 \%$ of the rodents during 1999 and 2000 were mostly bataviae and pyrogenes serovars (Phulsuksombati et al., 2001). Leptospires were also isolated from cows and buffaloes from the rice-fields. Research and development on rapid diagnostics and prevention and control of leptospirosis are being actively carried out in Thailand.

\section{Scrub Typhus}

Scrub typhus is the most common rickettsial infection in Thailand. It was first reported in Thailand in 1952 (Thainua, 1952). Prior to 1984 , less than 100 cases were reported annually. The number of patients with scrub typhus has been increasing steadily since 1985 as shown in Figure 9. This was due to an increased awareness and an 
improvement in laboratory diagnosis. It is likely that many cases of scrub typhus prior to 1984 were reported as acute pyrexia of unknown origin. It should be emphasized that scrub typhus is a common cause of acute pyrexia of unknown origin, as mentioned earlier. Cases were reported from all regions but more cases have been observed in the northeastern region, especially from the areas close to Cambodia and in the central region; this geographic distribution is similar to that of leptospirosis. The disease usually peaks during the rainy season of June and October. Most of the cases are among male farmers. Clinical features of scrub typhus are protean, and eschar (scab) is found in $0-55 \%$ of the patients (Sirisanthana and Poneprasert, 1989; Supparatpinyo et al., 1990; Silpapojakul et al., 1991).

Some patients with unrecognized scrub typhus may develop complications such as pneumonia, encephalitis, and meningitis. Doxycycline has been the antibiotic of choice for treating scrub typhus with a rapid clinical response. However Orientia tsutsugamushi is probably resistant to doxycycline; this has been observed in patients living in the northern part of Thailand (Watt et al., 1996). Macrolides such as azithromycin could be an alternative to doxycycline for treating scrub typhus (Watt et al., 1999). The case fatality rate over the past 6 years has usually been less than $0.5 \%$, as shown in Figure 9.

\section{DEVELOPMENT OF HEALTH SYSTEMS IN THAILAND}

\section{The Socioeconomic and Health Context}

Thailand, classified by the World Bank as a lower-middle income country, had a remarkable economic achievement during the 1980 s to the mid 1990s. Gross Domestic Product (GDP) per capita increased from 861 USD in 1986 to a peak of 3060 USD in 1996. The 1997 financial crisis in Thailand triggered the Asian economic crisis. In 1999, the GDP per capita was 6132 US\$PPP (purchasing power parity). Income distribution and poverty alleviation were among major government policies. Poverty reduction (in terms of the number of poor households) has been quite successful, but there has not been much achievement in improving income distribution. The discrepancy gap of income between the richest $10 \%$ to poorest $10 \%$ was 11.6. Data from the United Nations Development Program's Human Development Report shows that the gap between the richest $20 \%$ to poorest $20 \%$ was 7.6 , with a slowly improving GINI index of 41.4. In 2000 and 2001, per capita GDP dropped to the level of 1992 (1846 USD). GDP growth in 1997 and 1998 was minus $1.7 \%$ and minus $10.8 \%$. The economic recession had major negative consequences for all sectors of Thai society, including the health sector (Tangcharoensathien et al., 2000).

Since 2002, there have been promising signs of economic recovery. GDP growth in 2002 was $3.5 \%$ and was expected to increase to more than $5 \%$ in 2003 . The economic crisis had a major impact on the social sector but a lesser impact on the health sector despite government fiscal constraints (Tangcharoensathien et al., 2000).

Thailand has achieved a medium human development level, as measured by Human Development Index (HDI), of 0.757 in 1999. According to the UNDP's Human Development Report, there was a steady increasing trend of the HDI over the past two decades, rising from 0.603 in 1975 to 0.749 in 1995 . Thailand achieved the rank of 74 in the global league table of HDI for 2001, with an index of 0.768 . Life expectancy at birth in 2001 was 68.9 years, the adult literacy rate was 95.7, the combined primary, secondary, and tertiary gross enrollment ratio was 72, and GDP per capita US\$PPP was 6400 (United Nations Development Program, 2003).

Health achievement over the past two decades has also been also remarkable. A consistent reduction in total fertility rate (TFR) has been observed. The average TFR for 1995-2000 was 1.9, with a contraceptive 
prevalence rate of $72 \%$ (Population Reference Bureau, 2000). A health status profile indicated an infant mortality rate of $26 / 100,000$, an under five child mortality rate of $30 / 100,000$, and the maternal mortality rate in 1980-99 was $44 / 100,000$. The measles immunization rate for children aged one was as high as $94 \%$ and was sustained at this level for more than 10 years, while the percentage of births attended by skilled health staff in 1995-99 was 95\% (United Nations Development Program, 2003).

In terms of health care resources, there were an average of 24 physicians per 100,000 population for $1990-99$. In 1998 , the total health expenditure indicated that public sources comprised $1.9 \%$ of GDP, while private sources comprised $4.1 \%$ of GDP (notably household out of pocket). Per capita health expenditure was 349 US\$PPP. In 1999, the number of People Living with HIV/AIDS aged $15-49$ was $2.15 \%$, along with 305,000 women and 13,900 children $0-14$. The adult infection rate declined to $1.8 \%$ in 2001 (United Nations Development Program, 2003).

\section{Healthcare Delivery System}

Thailand has a pluralistic healthcare delivery system. Though the public sector, notably the Ministry of Public Health (MoPH), played a very key role in healthcare provision, the private sector, notably for-profit providers, also played an increasing role especially in the urban cities. Private hospital sector growth has been significant due to increased demand for private care among the middle classes, especially during the economic boom.

Since the five-year National SocioEconomic Development Plan of 1981-86, successive governments have placed a high importance on the development of the healthcare system, especially in the rural areas at district and sub-district level. A policy framework was laid out to achieve full coverage of district hospitals in all districts throughout the country in three successive five-year plans. The policy was implemented through adequate and sustained provision of financial and human resources. Since the early 1980s, the government has invested enormously in construction of 10 to 90 bed district hospitals in all districts. Subsequent policy also focused on full coverage of sub-district health centers to adequately provide care to local populations of about 5000 Thais. By the 7th National Socio-Economic Development Plan (19911996), healthcare infrastructure accomplished a very high geographical coverage (Ministry of Public Health, 2001). By 2001, there were 92 hospitals in 75 provinces outside Bangkok ( 25 regional and 67 general hospitals), 720 district hospitals in 795 districts (91\% coverage), and 9738 health centers in 7255 sub-districts ( $100 \%$ coverage). These infrastructures served as important hubs for the provision of integrated healthcare services including prevention, promotion, and curative services throughout the country. Subsequently, these hubs also enabled social mobilization towards good health.

The public sector played a major role in healthcare provision. In $2000,67 \%$ of total hospitals were owned by MoPH, $26 \%$ by the private sector, and $7 \%$ by other ministries. Some $64 \%$ of total hospital beds were owned by $\mathrm{MoPH}, 22 \%$ by private sector, and $14 \%$ by other ministries especially teaching hospitals. Private hospital bed share increased from $13 \%$ in 1991 to $22 \%$ in 2000 due to increasing demand for private medical care. Demand for private medical care was income elastic, and affected by the economic bust in 1998. Private healthcare market shrank significantly after the crisis, and a shift of utilization from private to public hospitals was observed (Putthasri et al., 2003).

It should be noted that local elected governments (especially municipalities) were comparatively weak in terms of healthcare service provision, leaving the MoPH to play a significant role. A Devolution Act was promulgated recently to increasingly transfer healthcare service responsibility to local elected governments, but local governments' readiness and capacity to handle healthcare services remains in question. 
Private hospitals have expanded their services in more affluent areas, such as provincial cities and metropolitan areas. A symbiotic relationship between public and private hospitals has been observed. Public doctors are allowed to have private practices during offhours either in their own private clinics or in private hospitals.

Since 1972, the government has enforced a three-year mandatory rural service among new medical, nursing, pharmacist, and dental graduates. Young graduates are posted in district hospitals all over the country. Positive incentives are included, such as a hardship allowance, and non-private practice incentives. Financial fines are levied against violators. This has significantly improved access to quality medical services by the vast majority of Thailand's rural population.

District health systems, typically comprised of district hospitals and 8-10 subdistrict health centers, contributed to the remarkable achievements of the Thailand National Family Planning policy in the last 25 years, as evidenced by the low TFR and a very high contraceptive prevalence rate. Nurses, midwives and doctors were trained to provide temporary and permanent methods of contraception through static clinics and mobile campaigns. District health systems also contributed to the achievement of high immunization coverage, significant reduction of vaccine preventable diseases, and mortality among children under age five. District health systems also serve as a major hub for disease surveillance, integrated control of diseases, and primary health care implementation.

District health systems have played a significant role in HIV/AIDS control and prevention, voluntary counseling and testing, primary prevention, safe sex campaigns, and treatment of opportunistic infections. It took only one year to scale up the Vertical Transmission Prevention Program of HIV throughout the country in 2001. Success factors were high antenatal care coverage, geographically accessible health centers, medical teams who provide counseling services, distribution of
AZT, and breast milk substitution. This reflected the system's resilience to successfully accommodate new programs in a short period. In 2003, district and provincial hospitals were major hubs for the provision of universal antiretroviral treatment.

Healthcare services were organized in three levels to promote rational use of resources and to foster effective referral systems. At the primary level, health centers provide primary care, and focus on prevention and promotion services, no hospitalization services are available. At the second level, district hospitals, staffed by several general practitioners, pharmacists, dentists, and a cadre of professional nurses provide secondary care including ambulatory, basic surgery, and hospitalization services. At the third level, provincial general hospitals staffed with specialists provide more sophisticated tertiary and sub-specialty medical services. MoPH regional hospitals and teaching hospitals mostly provide super-specialty care through referral systems.

\section{Human Resources for Health}

The government finances the education of most categories of health professionals including physicians, dentists, pharmacists, nurses and other paramedics, through general tax revenue. Student's tuition fees are low and do not reflect the true cost of education. Private nursing colleges play a very minor role in producing nurses. One difficulty is a national policy that fails to understand the demand for manpower in the private sector. In addition, there is neither a clear national policy toward private sector growth nor a strong regulatory capacity to steer and maximize the contributions of the private sector. As a result, there has been an internal brain drain of welltrained public Thai healthcare professionals toward the private sector, especially during the economic and private hospital boom periods. The heavy workload and relatively low pay scale and incentives in the public sector, contrasted with lower workload and higher 
TABLE 1. Top Twenty Conditions that Contribute to DALY in Thailand

\begin{tabular}{rlrrlrr}
\hline Rank & Male DALY & DALY & $\%$ & Female DALY & DALY & $\%$ \\
\hline 1 & HIV/AIDS & 960,087 & $17 \%$ & HIV/AIDS & 372,947 & $9 \%$ \\
2 & Traffic accidents & 510,907 & $9 \%$ & Stroke & 280,673 & $7 \%$ \\
3 & Stroke & 267,567 & $5 \%$ & Diabetes & 267,158 & $7 \%$ \\
4 & Liver cancer & 248,083 & $4 \%$ & Depression & 145,336 & $4 \%$ \\
5 & Diabetes & 168,372 & $3 \%$ & Liver cancer & 118,384 & $3 \%$ \\
6 & Ischemic heart disease & 164,094 & $3 \%$ & Osteoarthritis & 117,994 & $3 \%$ \\
7 & COPD (emphysema) & 156,861 & $3 \%$ & Traffic accidents & 114,963 & $3 \%$ \\
8 & Homicide and violence & 156,371 & $3 \%$ & Anemia & 112,990 & $3 \%$ \\
9 & Suicide & 147,988 & $3 \%$ & Ischemic heart diseases & 109,592 & $3 \%$ \\
10 & Drug dependence & 137,703 & $2 \%$ & Cataracts & 96,091 & $2 \%$ \\
11 & Alcohol dependence & 130,654 & $2 \%$ & COPD & 93,387 & $2 \%$ \\
12 & Cirrhosis & 117,527 & $2 \%$ & Deafness & 87,612 & $2 \%$ \\
13 & Lung cancer & 106,120 & $2 \%$ & Lower respiratory tract & 84,819 & $2 \%$ \\
& & & infections & & \\
14 & Drowning & 98,464 & $2 \%$ & Low birth weight & 83,879 & $2 \%$ \\
15 & Depression & 95,530 & $2 \%$ & Dementia & 70,191 & $2 \%$ \\
16 & Osteoarthritis & 93,749 & $2 \%$ & Anxiety disorders & 66,992 & $2 \%$ \\
17 & Tuberculosis & 93,695 & $2 \%$ & Schizophrenia & 60,800 & $2 \%$ \\
18 & Deafness & 93,497 & $2 \%$ & Tuberculosis & 60,643 & $2 \%$ \\
19 & Low birth weight & 91,934 & $2 \%$ & Birth trauma and asphyxia & 57,488 & $1 \%$ \\
20 & Anemia & 87,610 & $2 \%$ & Nephritis and nephrosis & 55,258 & $1 \%$ \\
& Total top 20 & $3,926,813$ & $70 \%$ & & $2,457,197$ & $62 \%$ \\
& Total national & $5,600,000$ & $100 \%$ & & $3,980,000$ & $100 \%$ \\
\hline
\end{tabular}

Source: Ministry of Public Health, Thailand, 2003b

pay in the private sector are primarily responsible for this internal drain. So far there has been no effective mechanism to prevent and mitigate this brain-drain problem. Policy solutions focus on a systematic analysis of parttime and full-time manpower arrangements between the two sectors. However, this solution faced very rigid bureaucratic rules and regulations.

\section{Burden of Diseases}

For the past 25 years, the development of Thailand's healthcare system focused on physical service expansions. There was an urgent need to look at how healthcare could better cope with the changing epidemiological profiles and burden of diseases. Rapid epidemiological transitions have occurred in Thailand, as the burden of disease shifts from communicable to non-communicable and lifestyle-related diseases. HIV/AIDS, Tuberculosis, Dengue hemorrhagic fever, and
Leptospirosis comprise an unfinished agenda of infectious diseases, while maternal and child health and nutritional problems have been significantly addressed.

A recent study on burden of disease (BOD) in 1999 estimated a total number of 5.6 million Disabled Adjusted Life Year (DALY) losses among men, and 4 million DALY losses among women (Ministry of Public Health, Thailand 2002). The top ten leading causes account for $52 \%$ and $44 \%$ of total national burden among men and women (Table 1).

In 1999, the three leading causes of DALY among men were HIV/AIDS, traffic injuries, and stroke. Among women, HIV/AIDS, stroke, and diabetes were three leading causes of DALY. Many of these causes are preventable by primary reduction of risks, notably through safe sex, effective traffic injury prevention, and tobacco consumption controls.

Three major risks contributing to Thailand's BOD were unsafe sex, alcohol, and 
tobacco among men, unsafe sex, high blood pressure, and overweight including obesity among women (Ministry of Public Health, 2003a). Alcohol was the second contributing risk factor for BOD among men. It can lead to domestic violence, major economic and life loss, and disability due to alcohol related injuries. Recent campaigns against drunk driving were not particularly successful and tougher law enforcement was required. Despite a decreasing trend in tobacco consumption due to successful public campaigns and tough law enforcement, the high prevalence of tobacco consumption in the past decades indicates that tobacco was the third and fourth major contributing factor for BOD in Thailand.

In summary, increasing Thailand's healthcare system capacity to effectively cope with chronic diseases such as diabetes, hypertension, and cardiovascular diseases is a major millennium challenge. In addition, enabling the system to provide primary prevention and risk reduction through social mobilization and behavior modification programs are further challenges, requiring a new mix of skills, attitudes and conceptual thinking among Thai healthcare workers and policymakers.

\section{Financing Healthcare, Insurance Coverage, and Recent Reform toward Universal Coverage}

Early in Thailand's healthcare history, user charges to patients were introduced and culturally accepted by patients. In the past, user charges were made on a voluntary basis through donation boxes or contribution in kind; subsequently charges became more formalized as bills. Revenue generated through user charges is kept at facility level to improve services. Non-budget revenue played a significant role in financing healthcare facilities. The government's policy on charging patients has been accompanied by an exemption policy for the poor. Exemption started first in 1975 , at the discretion of healthcare workers, as there were no government regulations. In 1981, exemption was implemented through a formal mechanism of means-testing for the issuance of a free care card for low-income households; an annual earmarked budget for free care to the poor was allocated to public health facilities. One article in the Thai Constitution stipulated clearly the government's responsibility to ensure the poor access to free care when needed.

Past governments employed a "piecemeal targeting approach" to increasing coverage for specific target population groups, starting first with a tax-financed Social Welfare Scheme for the poor (Tangcharoensathien et al., 2003). This is a means-testing scheme for low-income households. In 1992, the Scheme expanded to cover all elderly Thais over age 60 , acknowledging the population's lack of cash income to access healthcare. Children under age 12 were another targeted population for expansion in 1994. Though local leaders participated in the meanstesting exercises and recommended eligible households to the district authorities, due to nepotism at the very local level, the scheme neither adequately covered the real poor nor effectively excluded the non-poor from enjoying the Scheme (Tangcharoensathien et al., 2003).

Introduced in 1983, the Voluntary Health Card Scheme covers borderline populations who were not eligible for the social welfare scheme due to their income. This scheme has not performed well in term of coverage expansion and financing viability due to its structure. The voluntary nature of the scheme results in "adverse selection", whereby the sick participate and the healthy opt out the scheme. This results in financial non-viability in spite of more than $50 \%$ government subsidies. Stagnated coverage expansion has been observed.

Introduced in 1990, the Social Security Scheme (SSS) covers private sector employees. This is a tripartite (by the employee, the employer and the government) contributory scheme legislated in 1990. It gradually 
expanded coverage from private enterprises having more than twenty workers to ten, to five, and finally to one employee by April 2002. Unfortunately, beneficiaries are only the workers; to date no serious efforts have been made by the social security administration to expand its healthcare coverage to workers' spouses and dependents, despite huge surpluses of the social security fund. The strengths of the scheme were the application of a capitation contract model. It could very well contain healthcare costs, with simple and low administrative costs. Decent quality of care was provided to the social security workers though "cost-quality trade off" was one of the major weaknesses of the capitation system.

The employer liability Workmen Compensation Scheme, the predecessor of the Social Security Scheme, was designed to cover the work-related illnesses, injuries, disabilities, and death compensation to private sector employees. Employer contributions were formulated to account for the risk of each industry/business, plus an experience rate. Experience rate was meant to be a financial incentive (and vice versa disincentive) to encourage employers to introduce safety measures, but it was unsuccessful (Chunharas et al., 1999).

A tax financed Civil Servant Medical Benefit Scheme (CSMBS) generously covers current public employees, retired officials, and their three generation dependents, including spouses, parents, and three children under age 20 . This was a non-contributory welfare scheme. Inefficiency and poor financing value was observed in CSMBS, as it applied a "fee for service" retrospective reimbursement model.

During the past ten years of government efforts on coverage expansion, human resources were strengthened, experience was gained in insurance management, and lessons were learned about the strengths and weaknesses of different provider payment methods, notably fee for service and capitation models. Despite efforts made during the past 20 years, prior to October 2001, almost $30 \%$ of the population was not covered by any healthcare policy (Tangcharoesnathien et al., 2001). By October 2001, three major public schemes were covering the entire 62.5 million population, the UC, the CSMBS, and SSS. Figure 10 depicts the relationship among the three parties concerned-the insurance or purchaser agencies, the beneficiaries and patients, and the public-private health care providers. Flow of funds and services among these three stakeholders clearly illustrates their relationship (Tangcharoensathien et al., 2002).

The design of the benefits package and magnitude of the budget subsidy endorsed the "convergence principle" of closing down the existing gap of inequity among the three public insurance schemes (CSMBS, SSS and UC). Table 2 shows the trend of healthcare financing during 1995-2000 (WHO, 2002). WHO referred to National Health Account studies in 1994, 1996 and 1998 (Tangcharoensathien et al., 1999; Pongpanich et al., 2000), and reports on Thailand Health Profile (Ministry of Public Health, 2001). Total Health expenditure ranged $3.4 \%$ to $3.7 \%$ of GDP in 1995 to 2000 . Government expenditure on health as percent of total health expenditure increased from $48.9 \%$ to $57.4 \%$ in this period, as private expenditure on health declined.

When its targeting policies were exhausted, Thailand boldly adopted a policy of universal healthcare coverage. With strong political will by the major party-led coalition government, Thailand adopted universal healthcare coverage (UC) in October 2001. The UC incorporated the Social Welfare Scheme, the Voluntary Health Card Scheme, and the uninsured into a single form of coverage, to be financed by general tax revenue. It applied a low cost capitation contract model for ambulatory care, whereby beneficiaries were required to be registered with a provider, typically with a district health system (OECD, 1994). It also applied a global budget and case-mix (diagnostic related group) for inpatient services. A nominal payment (30 Baht, approximately 70 US cents) per ambulatory visit or admission at point of service was 


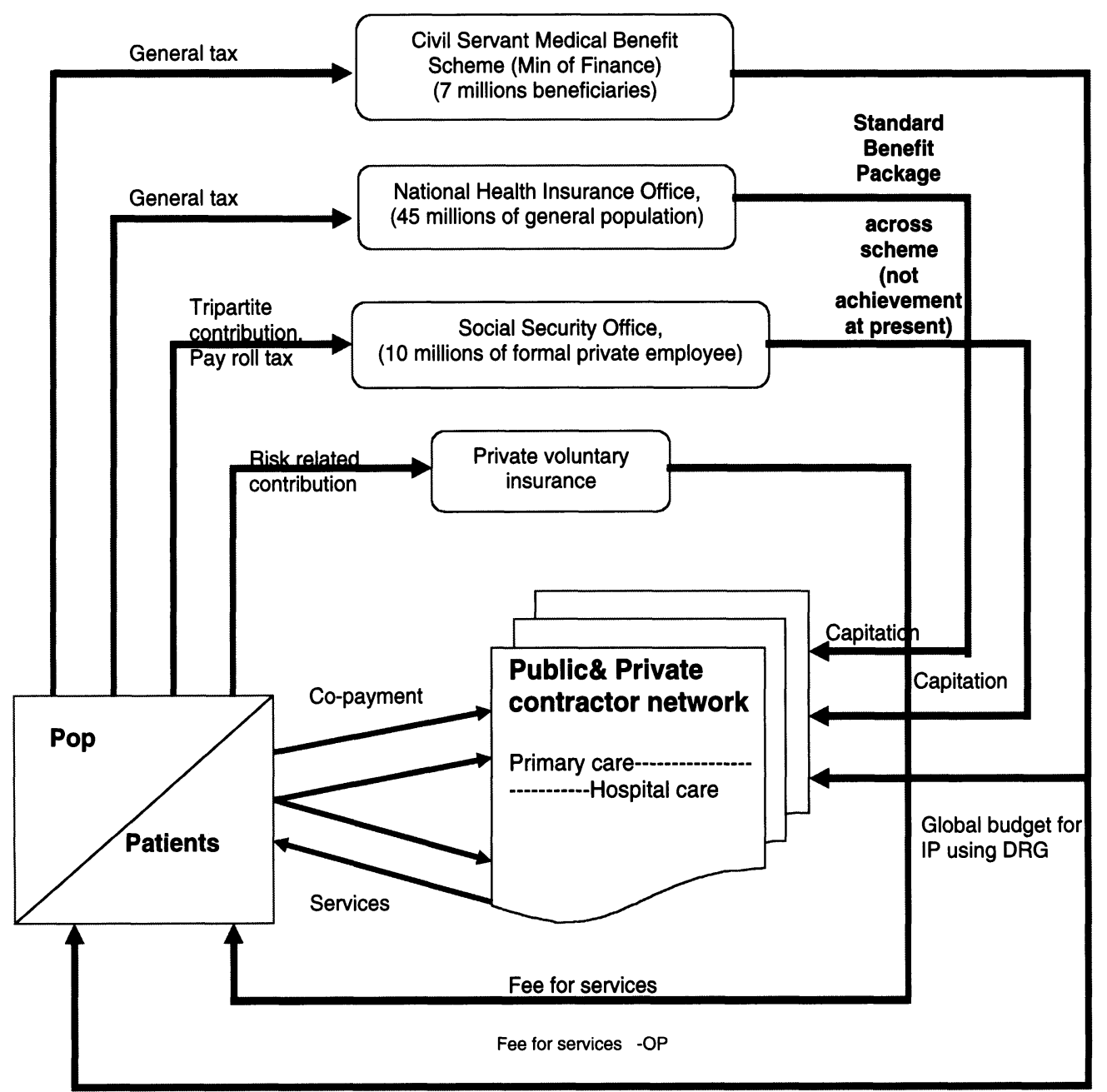

FIGURE 10. Model of health insurance system in Thailand, 2002 (Tangcharoensathien et al., 2002)

introduced, and again, the poor were exempted from this nominal fee.

\section{Future Challenges}

UC might significantly change the profile of Thailand's healthcare financing from the dominant role of household out-of-pocket payment towards tax funded public health insurance. Policy makers expect to see a diminishing proportion of households facing catastrophic illnesses. However, researchers need to monitor the beneficiaries of public spending, whether they are rich or poor, through
Benefit Incidence Analysis. Several national databases and household interview surveys are conducted by the National Statistical Office to provide evidence for policy monitoring and modification.

The low cost capitation contract model applied by both the Social Health Insurance plan in 1990 and more recently by the UC Scheme provided an enabling environment towards a more efficient healthcare system with rational use of resources. However, the possibility exists of a "cost quality tradeoff" of providing inadequate and poor services, under-prescription, and postponement 
TABLE 2. National Expenditure on Health in Thailand, 1995-2000, Current Year Price

\begin{tabular}{|c|c|c|c|c|c|c|}
\hline Expenditure ratios \& per capita levels & 1995 & 1996 & 1997 & 1998 & 1999 & 2000 \\
\hline Total Expenditure on Health (THE) \% GDP & 3.4 & 3.6 & 3.7 & 3.9 & 3.7 & 3.7 \\
\hline Government Expenditure on Health (GGHE) \% THE & 48.9 & 51.1 & 57.2 & 61.4 & 58.3 & 57.4 \\
\hline Private Expenditure on Health (PvtHE) \% THE & 51.1 & 48.9 & 42.8 & 38.6 & 41.7 & 42.6 \\
\hline GGHE $\%$ General Government Expenditure (GGE) & 8.1 & 9.6 & 10.9 & 13.3 & 11.4 & 11.4 \\
\hline $\begin{array}{l}\text { Social Security Expenditure on Health (SSHE) } \\
\quad \% \text { GGHE }\end{array}$ & 26.5 & 27.9 & 30.2 & 25.8 & 26.3 & 26.4 \\
\hline $\begin{array}{l}\text { External Resources funded Expenditure on Health } \\
\text { (ExtFHE) \% GGHE }\end{array}$ & 0.2 & 0.6 & 0.5 & 0.7 & 0.9 & 0.9 \\
\hline $\begin{array}{l}\text { Private Prepaid Plans Expenditure on Health } \\
\text { (PvtPPHE) \% PvtHE }\end{array}$ & 7.6 & 7.8 & 8.6 & 9.7 & 9.7 & 9.6 \\
\hline $\begin{array}{l}\text { Net Out-Of-Pocket Spending on health (OOPS) } \\
\quad \% \text { THE }\end{array}$ & 44.7 & 42.6 & 36.9 & 32.7 & 35.3 & 36.2 \\
\hline THE per capita at Exchange rate (US\$) & 97 & 110 & 93 & 71 & 73 & 71 \\
\hline GGHE per capita at Exchange-rate (US\$) & 47 & 56 & 53 & 44 & 43 & 41 \\
\hline THE per capita at International Dollar rate (\$) & 210 & 237 & 242 & 228 & 229 & 240 \\
\hline GGHE per capita at International Dollar rate (\$) & 103 & 121 & 138 & 140 & 133 & 138 \\
\hline
\end{tabular}

Source: Vasavid et al., 2003

of elective surgeries. This threat warrants prompt policy attention toward quality monitoring, accreditation of healthcare institutions, and audit. However, the geographical monopoly whereby consumers had no choice but their local District Health System, challenges attempts for tougher measures on quality. This requires a strong grievance mechanism and monitoring of performance among contractors.

Health systems need to address priority health problems indicated by BOD measurements. Social mobilization and empowerment of individuals and communities are the most crucial tools to increase societal momentum towards a healthy life style, physical fitness, and mental well-being. Additional government strategies include legislation and law enforcement to provide a favorable, healthy, and safe environment for all Thai citizens.

\section{LESSONS LEARNED FROM AIDS}

Thailand's knowledge of HIV/AIDS has increased significantly over the course of the epidemic. The following are some of the most important lessons that can be instructive to other countries as they cope with emerging HIV/AIDS issues.

It is important to accelerate surveillance of different phases of the disease as much as possible. In Thailand, the first government approach was one of denial of the possible consequences, and took about five years. Part of this time was spent performing seroepidemiology on a handful of cases in men having sex with men (MSM). A few small-scale studies showed low levels of prevalence among male sex workers. Later studies found high incidences in female sex workers in the Northern province. Ideally, primary phases of surveillance should be shortened through improvements of the surveillance systems.

A cohesive understanding of the extent to which HIV/AIDS can cause social, economical, ethical, legal, and international issues as well as medical and health problems, must be developed.

Top-level policymaking is also a highly desirable objective. One mechanism may be a national AIDS policy commission. Top politicians may lead this commission; in some countries, the prime minister may head this committee. Alternately, a Minister of Public Health or Minister without portfolio may be asked to lead the commission. It is very 
important to put such a commission in place as early as possible.

The composition of a National AIDS policy commission will have to be diverse, and include representatives of nongovernmental organizations (NGO), and others with a depth of knowledge about HIV/AIDS.

A National AIDS Commission should be able to bear some influence on the provincial level policymakers and staff. A provincial commission that is responsive to the national commission and able to implement policies is essential.

An important responsibility of a national HIV/AIDS policy commission is the allocation of the budget. The budget should be formulated as a \% of GDP or \% of the annual national budget.

It is necessary to realize that shifts in policy are possible at any time, depending on national and international politics, and other factors.

Major HIV/AIDS policy shifts can occur when there is a major shift in the healthcare structure of the country. For example, this has happened with the universal coverage policy in Thailand. There is currently controversy about whether AIDS patients will be covered in this scheme or not (WHO, 2002).

Increasing condom usage among sex workers has been successful, but programs propagating widespread use of condoms in the general population may not be as successful. As the epidemic changes and affects different sectors of Thai society, flexible policies and models of prevention are increasingly important.

Antiretroviral therapy for HIV/AIDS will occupy more of the AIDS budget as time goes on. The same may be true for the use of drugs to prevent mother to child transmission.

ACKNOWLedgements. The authors would like to thank Dr. Kumnuan Ungchusak and Dr. Waraluk Tangkanakul for valuable advice, Ms. Patcharin Tubviroj for secretarial assistance.

\section{REFERENCES}

Bamrungtrakul, T., Sunakorn, P., Sareebutara, W., Vejabhuti, A., Lochindarat, S., Teeraratkul, A., Kittikhun, P., Pinyosmosorn, R., Wasanawat, S., Darnswang, S.A., Chupuppakarn, S., Kusum, M., and Dejsirilert, S. (1994). Surveillance of antimicrobial resistance of Streptococcus pneumoniae and Haemophilus influenzae in Thailand. J Med Assoc Thai. 77:572579.

Barbazan, P., Yoksan, S., and Gonzalez, J.P. (2002). Dengue hemorrhagic fever epidemiology in Thailand: Description and forecasting of epidemics. $M i$ crobes and Infection 4(7): 699-705.

Beek, S.V. (2001). Fears and Concerns in Bangkok Then and Now. AB Publications, Nonthaburi, Thailand. pp. 85-93.

Bodhidatta, L., Vithayasai, N., Eimpokalarp, B., Pitarangsi, C., Serichantalergs, and Isenbarger, D.W. (2002). Bacterial enteric pathogens in children with acute dysentery in Thailand: Increasing importance of quinolone-resistant Campylobacter. Southeast Asian J Trop Med Public Health 33(4): 752757.

Bumrasnaradul, P. (1967). In memory of Ministry of Public Health's 25th Anniversary. Mitrnara Printing, Bangkok, pp. 672-676.

Chareonviriyaphap, T., Bangs, M.J., and Ratanatham, S. (2000). Status of malaria in Thailand. Southeast Asian J Trop Med Public Health 31(2): 225-237.

Children's Hospital, Bangkok. (2000). Annual Report. Bangkok.

Children's Hospital, Bangkok. (2001). Annual Report. Bangkok.

Chunharas, S., Charoenparij, S., Donaldson, D., Kraushaar, D., Pinjaroen, S., Srivanichakorn, S., Suriyawongpaisal, P., Pannorunothai, S., Tangcharoensathien, V., and Valyasevi, A. (1999). Thailand: Health Management and Financing Study Project ADB no. 2997- The final integrated report. February 23, 1999. Health Systems Research Institute and MSH, Bangkok.

Congpuong, K., Na-Bangchang, K., Thimasarn, K., Tasanor, U., and Wernsdorfer, W.H. (2002). Sensitivity of Plasmodium vivax to chloroquine in $\mathrm{Sa}$ Kaeo Province, Thailand. Acta Trop. 83(2): 117121.

Dejsirilert, S., Overweg, K., Sluijter, M., Saengsuk, L., Gratten, M., Ezaki, T., and Hermans, P.W. (1999). Nasopharyngeal carriage of penicillinresistant Streptococcus pneumoniae among children with acute respiratory tract infections in Thailand: A molecular epidemiological survey. Journal of Clinical Microbiology 37(6): 1832-1838.

Endy, T.P., Chunsuttiwat, S., Nisalak, A., Libraty, D.H., Green, S., Rothman, A.L., Vaughn, D.W., and Ennis, F.A. (2002). Epidemiology of inapparent 
and symptomatic acute dengue virus infection: A prospective study of primary school children in Kamphaeng Phet, Thailand. Am J Epidemiol. 156(1): 40-51.

Isenbarger, D.W., Hoge, C.W., Srijan, A., Pitarangsi, C., Vithayasai, N., Bodhidatta, L., Hickey, K.W., and Cam, P.D. (2002). Comparative antibiotic resistance of diarrheal pathogens from Vietnam and Thailand, 1996-1999. Emerg Infect Dis. 8(2): 175180.

Kamolratanakul, P., Hiransuthikul, N., Singhadong, N., Kasetjaroen, Y., Akksilp, S., and Lertmaharit, S. (2002). Cost analysis of different types of tuberculosis patients at tuberculosis centers in Thailand. Southeast Asian J Trop Med Public Health 33(2): 321-330.

Kantachuvessiri, A. (2002). Dengue hemorrhagic fever in Thai society. Southeast Asian J Trop Med Public Health 33(1): 56-62.

Kingnate, D., Sagarasaeranee, P., and Choomkasien, P. (1997). Thailand Rabies control (human side). In: Third International Symposium on Rabies Control in Asia, Wuhan, China. Elsevier, Paris, pp. 194 196.

Kositanont, U., Naigowit, P., Imvithaya, A., Singchai, C., and Puthavathana, P. (2003). Prevalence of antibodies to Leptospira serovars in rodents and shrews trapped in low and high endemic areas in Thailand. J Med Assoc Thai. 86(2): 136-142.

Kusum, M. (1999). National Antimicrobial Resistance Surveillance, Thailand. Ministry of Public Health, Department of Medical Sciences, Thailand.

Leelarasamee, A. (2000). Acute febrile illness of unknown origin: A prevalence study in Thailand. In: Aswapokee, N., Leelasupasri, S., Likitnukul, S., (eds.), Infectious Diseases beyond 2000. Holistic Publishings Co., Bangkok, pp. 59-78.

Maneekarn, N., and Ushijima, H. (2000). Epidemiology of rotavirus infection in Thailand. Pediat Int. 42(4): $415-421$.

Ministry of Public Health, Thailand. (1977-2002). Annual Epidemiological Surveillance Reports. Bureau of Epidemiology, Department of Disease Control. (multiple years).

Ministry of Public Health, Thailand. (1981). Division of Communicable Diseases Control, Proceedings of National Workshop on Acute Respiratory Infections in Children. Sahaprachapanich Printing, Bangkok.

Ministry of Public Health, Thailand. (1998). Drug Resistance Surveillance. Department of Medical Sciences.

Ministry of Public Health, Thailand. (2001). Health Policy and Planning Bureau. Thailand Health Profile. Nonthaburi, Thailand.

Ministry of Public Health, Thailand. (2002). Burden of Disease and Injuries in Thailand, Priority Setting for Policy. The Thai Working Group on Burden of
Disease and Injuries, Bureau of Health Policy and Planning. (November 2002).

Ministry of Public Health, Thailand. (2003a). Attributable risk for burden of disease in Thailand, A preliminary report. The Thai Working Group on Burden of Disease and Injuries, Bureau of Health Policy and Planning, Thailand.

Ministry of Public Health, Thailand. (2003b). The Burden of Diseases in Thailand. Thai Working Group on Burden of Disease and Injuries, Bureau of Health Policy and Planning, Nonthaburi.

Murphy, G.S. Jr., Echeverria, P., Jackson, L.R., Arness, M.K., LeBron, C., and Pitarangsi, C. (1996). Ciprofloxacin- and azithromycin-resistant Campylobacter causing traveler's diarrhea in U.S. troops deployed to Thailand in 1994. Clin Infect Dis. 22(5): 868-869.

Nimmannitya, S., Thisyakorn, U., and Hemsrichart. V. (1987). Dengue haemorrhagic fever with unusual manifestations. Southeast Asian J Trop Med Public Health 18(3): 398-406.

Nisalak, A., Endy, T.P., Nimmannitya, S., Kalayanarooj, S., Thisayakorn, U., Scott, R.M., Burke, D.S., Hoke, C.H., Innis, B.L., and Vaughn, D.W. (2003). Serotype-specific dengue virus circulation and dengue disease in Bangkok, Thailand. Am J Trop Med Hyg. 68(2): 191-202.

Organization of Economic Cooperation and Development. (1994). The Reform of Seven OECD countries. OECD Publishing, Paris.

Panaphut, T,. Domrongkitchaiporn, S., Vibhagool, A., Thinkamrop, B., and Susaengrat, W. (2003). Ceftriaxone compared with sodium penicillin $\mathrm{g}$ for treatment of severe leptospirosis. Clin Infect Dis. 36(12): 1507-1513.

Pancharoen, C., and Thisyakorn, U. (2001). Neurological manifestations in dengue patients. Southeast Asian J Trop Med Public Health 32(2): 341-345.

Panichabhongse, P. (2001). The Epidemiology of Rabies in Thailand. A thesis presented in partial fulfilment of the requirement for the degree of Master of Veterinary Studies, Massey University, Palmerston North, New Zealand. (unpublished paper).

Phulsuksombati, D., Sangjun, N., Khoprasert, Y., Kingnate, D., and Tangkanakul, W. (2001). Leptospires in rodent, northeastern region 1999-2000. Health Sci. 10(3): 516-525.

Pleumpanupat, W., Jittimanee, S., Akarasewi, P., Rienthong, S., Jittimanee, S., Chiewlian, Y., Phunpruk, S., Malainual, C., Ngamtrairai, N., and Adedipe, A. (2003). Resistance to anti-tuberculosis drugs among smear-positive cases in Thai prisons 2 years after the implementation of the DOTS strategy. Int $J$ Tuberc Lung Dis. 7(5): 472-477.

Pongpanich, S., Tantigate, N., Srithamrongsawat, S., Vasavid, C., and Vimolkij, D. (2000). National Health Accounts for 1998 and 1999. A Research 
Report. Health Systems Research Institute, Bangkok.

Population Reference Bureau. (2000). The 2000 World Population Data Sheet of the Population Bureau. PBR, Washington DC.

Punnotok, J., Shaffer, N., Naiwatanakul, T., Pumprueg, U., Subhannachart, P., Ittiravivongs, A., Chuchotthaworn, C., Ponglertnapagorn, P., Chantharojwong, N., Young, N.L., Limpakarnjanarat, K., and Mastro, T.D. (2000). Human immunodeficiency virusrelated tuberculosis and primary drug resistance in Bangkok, Thailand. Int J Tuberc Lung Dis. 4(6): 537-543.

Putong, N.M., Pitisuttithum, P., Supanaranond, W., Phonrat, B., Tansuphasawadikul, S., Silachamroon, U., Yuda, H.C., Bussaratid, V., and Aswapokee, N. (2002). Mycobacterium tuberculosis infection among HIV/AIDS patients in Thailand: clinical manifestations and outcomes. Southeast Asian $J$ Trop Med Public Health 33(2): 346-351.

Putthasri, W., Saithanu, S., and Tangcharoensathien, V. (2003). Private Industry in Thailand after the economic crisis (1996-2001): Role and coping mechanisms. International Health Policy Program, Nonthaburi, Thailand.

Reechaipichitkul, W. (2002). Multidrug-resistant tuberculosis at Srinagarind Hospital, Khon Kaen, Thailand. Southeast Asian J Trop Med Public Health 33(3): 570-574.

Sabchareon, A., Lang, J., Chanthavanich, P., Yoksan, S., Forrat, R., Attanath, P., Sirivichayakul, C., Pengsaa, K., Pojjaroen-Anant, C., Chokejindachai, W., Jagsudee, A., Saluzzo, J.F., and Bhamarapravati, N. (2002). Safety and immunogenicity of tetravalent live-attenuated dengue vaccines in Thai adult volunteers: Role of serotype concentration, ratio, and multiple doses. Am J Trop Med Hyg. 66(3): 264-272.

Silpapojakul, K., Chupuppakarn, S., Yuthasompob, S., Varachit, B., Chaipak, D., Borkerd, T., and Silpapojakul, K. (1991). Scrub and murine typhus in children with obscure fever in the tropics. Ped Infect Dis J. 10(3): 200-203.

Silpapojakul, K., Chayakul, P., Krisanapan, S., and Silpapojakul, K. (1993). Murine typhus in Thailand: Clinical features, diagnosis and treatment. Quarterly Journal of Medicine 86(1): 43-47.

Siriarayapon, P., Yanai, H., Glynn, J.R., Yanpaisarn, S., and Uthaivoravit, W. (2002). The evolving epidemiology of HIV infection and tuberculosis in northern Thailand. J Acquir Imm Defic Syndr. 31(1): 80-89.

Sirisanthana, T., Pinyopornpanit, V., Sirisanthana, V., Strickman, D., Kelly, D.J., and Dasch, G.A. (1994). First cases of spotted fever group rickettsiosis in Thailand. Am J Trop Med Hyg. 50(6): 682-686.
Sirisanthana, V., and Poneprasert, B. (1989). Scrub typhus in the children at Chiang Mai University Hospital. J Infect Antimicrob Agents 6: 22-27.

Siritantikorn, S., Puthavathana, P., Suwanjutha, S., Chantarojanasiri, T., Sunakorn, P., Ratanadilok Na Phuket, T., Nawanopparatsakul, S., Teeyapaiboonsilpa, P., Taveepvoradej, S., Pengmesri, J., and Pongpate, S. (2002). Acute viral lower respiratory infections in children in a rural community in Thailand. J Med Assoc Thai. 85(Suppl 4): S1167-S1175.

Sriyabhaya, N., Payanandana, V., Bamrungtrakul, T., and Konjanart, S. (1993). Status of tuberculosis control in Thailand. Southeast Asian J Trop Med \& Public Health 24(3): 410-419.

Stephens, H.A., Klaythong, R., Sirikong, M., Vaughn, D.W., Green, S., Kalayanarooj, S., Endy, T.P., Libraty, D.H., Nisalak, A., Innis, B.L., Rothman, A.L., Ennis, F.A., and Chandanayingyong, D. (2002). HLA-A and -B allele associations with secondary dengue virus infections correlate with disease severity and the infecting viral serotype in ethnic Thais. Tissue Antigens 60(4): 309-318.

Sunakorn, P., Chunchit, L., Niltawat, S., Wangweerawong, M., and Jacobs, R.F. (1990). Epidemiology of acute respiratory infections in young children from Thailand. Ped Infect Dis J. 9(12): 873-877.

Supparatpinyo, K., Horsin, P., and Hirunsri, P. (1990). Scrub typhus at Maharaj Nakorn Chiang Mai Hospital : A study of 60 cases. Internal Medicine 6: 6-10.

Suputtamongkol, Y., Rolain, J.M., Losuwanaruk, K., Niwatayakul ,K., Suthinont, C., Chierakul, W., Pimda, K., and Raoult, D. (2003). Q fever in Thailand. Emerg Infect Dis. 9(9): 1186-1188.

Suwanjutha, S., Chantarojanasiri, T., Watthana-kasetr, S., Sirinavin, S., Ruangkanchanasetr, S., Hotrakitya, S., Wasi, C., and Puthavathana, P. (1990). A study of nonbacterial agents of acute lower respiratory tract infection in Thai children. Rev Infect Dis. 12(Suppl 8): S923-S928.

Suwanjutha, S., Sunakorn, P., Chantarojanasiri, T., Siritantikorn, S., Nawanoparatkul, S., Rattanadilok Na Bhuket, T., Teeyapaiboonsilpa, P., Preutthipan, A., Sareebutr, W., and Puthavathana, P. (2002). Respiratory syncytial virus-associated lower respiratory tract infection in under-5-year-old children in a rural community of central Thailand, a populationbased study. J Med Assoc Thai. 85(Suppl 4): S1111-119.

Tangcharoensathien, V., Laixuthai, A., Vasavid, J., Tantigate, N., Prajuabmoh-Ruffalo, W., Vimolkit,D., and Lertiendumrong, J. (1999). National Health Account Development: Lessons from Thailand. Health Policy and Planning 14(4): 342-353.

Tangcharoensathien, V., Harnvoravongchai, P., Pitayarangsarit, and S., Kasemsup, V., (2000). Health 
impacts of rapid economic changes in Thailand. Social Science and Medicine 51: 789-807.

Tangcharoesnathien, V., Srithamrongswat, S., and Pittayarangsarit, S. (2001). Overview of health insurance systems. In: Thammathat-aree, J. (ed). Health Insurance Systems in Thailand. Health Systems Research Institute, Desire Publishing, Bangkok.

Tangcharoensathien, V., Tantivess, S., Teerawattananon, Y., Auamkul, N., and Jongudoumsuk, P. (2002). Universal coverage and impact on reproductive health service in Thailand. Reproductive Health Matters 10(20): 59-69.

Tangcharoensathien, V., Teokul, W., Chanwongpaisal, L. (2003). Social Welfare System in Thailand: A challenge from targeting to universality. A paper presented at United Nations Research Institute for Social Development (UNRISD) workshop on Social Policy in a Development Context: Transforming the Developmental Welfare State in East Asia, 30 June-1 July 2003, Novotel, Bangkok, Thailand.

Tangkanakul, W. (2002). Leptospirosis. In: Department of Disease Control, Ministry of Public Health, Thailand (ed.), Important Infectious Diseases 2001, Agricultural Co-Operation Printing, pp. 53-56.

Tangkanakul, W., Tharmaphornpilm P., Plikaytis, B.D., Bragg, S., Poonsuksombat, D., Choomkasien, P., Kingnate, D., and Ashford, D.A. (2000). Risk factors associated with leptospirosis in northeastern Thailand, 1998. Am J Trop Med Hyg. 63(3-4): 204208.

Tangkanakul, W., Siriarayaporn, P., Pool, T., Ungchusak, K., and Chunsuttiwat, S. (2001). Environmental and travel factors related to leptospirosis in Thailand. $J$ Med Assoc Thailand 84(12): 1674-1680.

Thaikruea, L., Charearnsook, O., Reanphumkarnkit, S., Dissomboon, P., Phonjan, R., Ratchbud, S., Kounsang, Y., and Buranapiyawong, D. (1997). Chikungunya in Thailand: A re-emerging disease? Southeast Asian J Trop Med Public Health 28(2): 359364.

Thainua, M. (1952). A case report of scrub typhus. J Med Assoc Thai. 35: 9-27.

Ungchusak, K., and Kunasol, P. (1987). Dengue haemorrhagic fever in Thailand, 1987. Southeast Asian J Trop Med Public Health 19(3): 487-490.

United Nations Development Program. (2003). Human Development Report. UNDP, New York.

Vathanophas, K., Sangchai, R., Raktham, S., Pariyanonda, A., Thangsuvan, J., Bunyaratabhandu, P., Athipanyakom, S., Suwanjutha, S., Jayanetra, P., Wasi, C., Vorachit, M., and Puthawatana, P. (1990). A community-based study of acute respiratory tract infection in Thai children. Rev Infect Dis. 12(Suppl 8): S957-S965.

Vaughn, D.W., Green, S., Kalayanarooj, S., Innis, B.L., Nimmannitya, S., Suntayakorn, S., Endy, T.P.,
Raengsakulrach, B., Rothman, A.L., Ennis, F.A., and Nisalak, A. (2000). Dengue viremia titer, antibody response pattern and virus serotype correlate with disease severity. J Infect Dis. 181(1): 2-9.

Vasavid, C., Tisayatikom, K., Patcharanarumol, W., and Tangcharoensathien, V. (2003). Thailand National Health Account. A research report. Ministry of Public Health, International Health Policy Program. Nonthaburi.

Wangroongsarb, P, Petkanchanapong, W., Yasaeng, S., Imvithaya, A., and Naigowit, P. (2002). Survey of leptospirosis among rodents in epidemic areas of Thailand. J Trop Med Parasitol. 25(2): 56-58.

Watt, G., and Jongsakul, K. (2003). Acute undifferentiated fever caused by infection with Japanese encephalitis virus. Am J Trop Med Hyg. 68(6): 704706.

Watt, G., Chouriyagun,e C., Ruangweerayud, R., Watcharapichat, P., Phulsuksombati, D., Jongsakul, K., Teja-Isavadharm, P., Bhodhidatta, D., Corcoran, K.D., Dasch, G.A., and Strickman, D. (1996). Scrub typhus infections poorly responsive to antibiotics in northern Thailand. Lancet 348(9020): 86-89.

Watt, G., Kantipong, P., Jongsakul, K., Watcharapichat, P., and Phulsuksombati, D. (1999). Azithromycin activities against Orientia tsutsugamushi strains isolated in cases of scrub typhus in Northern Thailand. Antimicrob. Agents Chemother. 43(11): 28172818.

Wiwanitkit, V. (2002). High prevalence of malaria in Myanmar migrant workers in a rural district near the Thailand-Myanmar border. Scand J Infect Dis. 34(3): 236-237.

Wongsrichanalai, C., Pickard, A.L., Wernsdorfer, W.H., and Meshnickd, S.R. (2002). Epidemiology of drugresistant malaria. Lancet Infectious Diseases 2(4): 209-218.

World Health Organization. (2002). National Health Expenditure, Thailand. WHO, Geneva.

Wright, A., and Breakspears, O.T. (1903). Twentieth Century Impressions of Siam. Health and Hospitals. Lloyd Greater Britain Publishing Company. pp. 128-134.

Yanai, H., Uthaivoravit, W., Panich, V., Sawanpanyalert, P., Chaimanee, B., Akarasewi, P., Limpakarnjanarat, K., Nieburg, P., and Mastro, T.D. (1996). Rapid increase in HIV-related tuberculosis, Chiang Rai, Thailand, 1990-1994. AIDS 10(5): 527-531.

Yanai, H., Uthaivoravit, W., Mastro, T.D., Limpakarnjanarat, K., Sawanpanyalert, P., Morrow, R.H. Jr., and Nieburg, P. (1997). Utility of tuberculin and anergy skin testing in predicting tuberculosis infection in human immunodeficiency virus-infected persons in Thailand. Int $J$ Tuberc Lung Dis. 1(5): $427-434$. 
Yanai, H., Limpakarnjanarat, K., Uthaivoravit, W., Mastro, T.D., Mori, T., and Tappero, J.W. (2003). Risk of Mycobacterium tuberculosis infection and disease among health care workers, Chiang Rai, Thailand. Int J Tuberc Lung Dis. 7(1): 36-45.

Yoshiyama, T., Supawitkul, S., Kunyanone, N., Riengthong, D., Yanai, H., Abe, C., Ishikawa, N., Akarasewi,
P., Payanandana, V., and Mori, T. (2001). Prevalence of drug-resistant tuberculosis in an HIV endemic area in northern Thailand. Int $J$ Tuberc Lung Dis. 5(1): 32-39.

Yunibandu, J. (1943). First report of Weil's disease in Thailand. J Med Assoc Thailand 26: 83139. 